\title{
AVALIAÇÃO DE DESEMPENHO NA GESTÃO ESTRATÉGICA ORGANIZACIONAL: SELEÇÃO DE UM REFERENCIAL TEÓRICO DE PESQUISA E ANÁLISE BIBLIOMÉTRICA
}

\section{PERFORMANCE EVALUATION IN ORGANIZATIONAL STRATEGIC MANAGEMENT: A THEORETICAL FRAMEWORK SELECTION AND BIBLIOMETRIC ANALYSIS}

\author{
Caroline Rodrigues Vaz ${ }^{1}$ Jorge Eduardo Tasca ${ }^{2}$; Leonardo Ensslin ${ }^{3}$; Sandra Rolim Ensslin ${ }^{4}$; Paulo \\ Mauricio Selig ${ }^{5}$ \\ ${ }^{1}$ Universidade Federal de Santa Catarina - UFSC - Florianópolis - Brasil \\ caroline-vaz@hotmail.com \\ ${ }^{2}$ Universidade Federal de Santa Catarina - UFSC - Florianópolis - Brasil \\ jorgetasca@gmail.com \\ ${ }^{3}$ Universidade Federal de Santa Catarina - UFSC - Florianópolis - Brasil \\ leonardoensslin@gmail.com \\ ${ }^{4}$ Universidade Federal de Santa Catarina - UFSC - Florianópolis - Brasil \\ sensslin@gmail.com \\ ${ }^{5}$ Universidade Federal de Santa Catarina - UFSC - Florianópolis - Brasil \\ selig@deps.ufsc.br
}

\begin{abstract}
Resumo
A preocupação em abordar esta temática decorre da relevância da gestão estratégica, como um elemento central para as organizações em sua busca constante de vantagem competitiva, agregando um novo elemento neste cenário, o desempenho organizacional. As organizações empregam variadas formas de avaliar sua performance, com destaque para os indicadores numéricos ou quantitativos destinados a estabelecer metas, padrões e objetivos para melhorar o desempenho organizacional. Este artigo tem como objetivo realizar a seleção de um referencial teórico relacionado à temática gestão estratégica organizacional, sob o enfoque da avaliação de desempenho, por meio de um processo estruturado denominado ProKnow-C (Knowledge Development Process - Constructivist), bem como desenvolver a análise bibliométrica deste portfólio bibliográfico, evidenciando os artigos, autores e periódicos mais alinhados ao tema e com maior relevância acadêmica na amostra. O processo permitiu construir um portfólio bibliográfico composto por 12 artigos, selecionados em quatro bases de dados internacionais. Na análise bibliométrica foram analisados os artigos do portfólio selecionado e suas referências bibliográficas, permitindo apurar, para a amostra, os artigos mais relevantes, os autores, as palavras-chave e os periódicos que mais publicaram sobre o assunto em questão.
\end{abstract}

Palavras-chave: avaliação de desempenho; gestão estratégica organizacional; ProKnow-C; análise bibliométrica. 


\section{Introdução}

O trabalho desenvolvido neste artigo envolve a seleção de um referencial teórico para gestão estratégica organizacional sob a ótica da avaliação de desempenho. No bojo de um estudo mais amplo, o presente artigo direciona sua atenção para uma revisão da literatura e seleção de um portfólio bibliográfico destinado à composição de um quadro teórico relacionado à avaliação de desempenho no contexto da gestão estratégica.

A preocupação em abordar esta temática decorre da relevância da gestão estratégica, como um elemento central para as organizações em sua busca constante de vantagem competitiva (MORGAN e STRONG, 2003). Desta forma, as organizações têm carreado recursos e esforços no sentido de compreender os motivos pelos quais determinadas empresas alcançam desempenhos de excelência e angariam vantagem competitiva sustentável, enquanto outras não (O'REGAN e GHOBADIAN, 2004).

Para isso, no entanto, é fundamental a compreensão do significado de estratégia organizacional. Mintizberg e Quinn (2001) afirmam que, mesmo havendo divergências práticas e teóricas sobre este tema, é possível encontrar pontos de convergência em relação aos aspectos que definem e integram o conceito de estratégia organizacional, conforme segue:

a) A estratégia trabalha a interação entre a organização e o ambiente em que está inserida;

b) A estratégia alcança toda a organização; decisões estratégicas envolvem e comprometem os colaboradores, muitas vezes, levando-os a sair de uma situação estável e conhecida para um novo contexto, nem sempre favorável a todos;

c) A estratégia reclama a adesão e a plena participação de todos colaboradores da organização;

d) Existem diferentes níveis de estratégia: estratégias corporativas (definição dos princípios de negócio); estratégias de negócio (formas de competição em cada negócio); estratégias de produção (para o alcance de objetivos pré-estabelecidos em determinadas áreas da organização); e,

e) As estratégias envolvem dimensões conceituais e analíticas. Alguns autores ressaltam os aspectos analíticos da estratégia mais do que os outros. No entanto, a maioria afirma que o alicerce da estratégia está na dimensão conceitual desenvolvida pelos líderes da organização.

A diversidade de compreensão e de alcance do significado do termo estratégia organizacional foi sistematizada e organizada, segundo Mintzberg, Ahlstrand e Lampel (2000), em escolas de pensamento estratégico, cuja síntese segue apresentada no Quadro 1. 
Quadro 1 - Escolas de pensamento estratégico

\begin{tabular}{|c|c|c|}
\hline Escola & $\begin{array}{c}\text { Formulação } \\
\text { de estratégia } \\
\text { como processo }\end{array}$ & Descrição \\
\hline \multicolumn{3}{|r|}{ Escolas prescritivas } \\
\hline Design & Conceitual & $\begin{array}{l}\text { O principal papel do gestor é analítico. O pensar precede a ação para } \\
\text { enfrentar com competência a necessidade de entender os ambientes e } \\
\text { relacionar os pontos fortes e fracos da organização com suas ameaças e } \\
\text { oportunidades, para assim estabelecer a estratégia a ser seguida. Por outro } \\
\text { lado, a escola do design aborda, também, embora com menor clareza e } \\
\text { ênfase, os valores do gestor e sua responsabilidade social, como aspectos } \\
\text { que influenciam a escolha da estratégia. Segundo essa escola, a concepção } \\
\text { de estratégia deve trazer simplicidade às organizações, entre outras razões, } \\
\text { por estar sob a responsabilidade - formulação e controle -, tão-somente, do } \\
\text { executivo principal. }\end{array}$ \\
\hline Planejamento & Formal & $\begin{array}{l}\text { No planejamento, assim como no design, o executivo principal é quem } \\
\text { detém o poder sobre as decisões e planos estratégicos, embora, na prática, } \\
\text { deva aprovar, e não mais propriamente conceber tais planos. Nessa escola, } \\
\text { os planejadores profissionais são os principais atores do processo. As } \\
\text { estratégias que emergem desse processo devem ser explicitadas, no sentido } \\
\text { de que possam ser implementadas com atenção nos objetivos, nos } \\
\text { orçamentos, nos programas e nos planos operacionais (apropriados ao seu } \\
\text { lema: prever e preparar). Aqui, o planejamento passa a ser muito } \\
\text { fortemente associado à ideia de controle, principalmente em função da } \\
\text { formalidade de sua elaboração e à mecanização do processo. }\end{array}$ \\
\hline Posicionamento & Analítico & $\begin{array}{l}\text { A formulação da estratégia continua como um processo controlado, formal } \\
\text { e, portanto, consciente, produzindo estratégias deliberadas que devem ser } \\
\text { evidenciadas antes da implementação. Como nas escolas anteriores, seu } \\
\text { foco está na observação e formação (baseado na seleção de posições } \\
\text { estratégicas genéricas). Esta escola ignora a etapa de implementação das } \\
\text { estratégias. }\end{array}$ \\
\hline \multicolumn{3}{|r|}{ Escolas descritivas } \\
\hline Empreendedora & Visionário & $\begin{array}{l}\text { Assim como a do posicionamento, esta escola tem origem em alguns } \\
\text { estudos de economia, nesse caso, porém, naqueles em que o empreendedor } \\
\text { tem papel proeminente. Diferentemente de todas as escolas anteriores, a } \\
\text { escola empreendedora tem natureza descritiva e não prescritiva. O processo } \\
\text { é focado em um único líder, no entanto, o entendimento da estratégia como } \\
\text { perspectiva (conceito de visão), traz o foco de seus componentes para a } \\
\text { representação mental da estratégia (provinda da natureza visionária do } \\
\text { líder). É essa característica que daria ao líder empreendedor um senso de } \\
\text { direção de longo prazo, uma perspectiva de futuro da organização. O líder } \\
\text { promoveria a visão de forma decidida, mantendo o controle pessoal da sua } \\
\text { implementação (o que não é muito explorado) dando-lhe, como } \\
\text { consequência, um caráter mais flexível. }\end{array}$ \\
\hline Cognitiva & Mental & $\begin{array}{l}\text { A escola cognitiva procura entender o funcionamento do cérebro humano } \\
\text { para compreender como, a partir da percepção (observação) da realidade, } \\
\text { formam-se as estratégias na mente do estrategista. Assim, pode-se } \\
\text { reconhecer o foco dessa escola, não nas estratégias em si, mas em seu } \\
\text { processo de derivação da realidade, percebida no âmbito da psicologia } \\
\text { cognitiva. Para os autores dessa escola os estrategistas são autodidatas que } \\
\text { desenvolvem sua estrutura de conhecimento e seus processos de } \\
\text { pensamento por experiência direta. }\end{array}$ \\
\hline Aprendizado & Emergente & $\begin{array}{l}\text { Suas premissas passam pelo aprendizado coletivo, e emergente de forma } \\
\text { deliberada, em que os atores são comprometidos com os resultados globais. } \\
\text { Os padrões aqui emergentes podem, e devem ser internalizados à estratégia } \\
\text { formal. }\end{array}$ \\
\hline Poder & De negociação & $\begin{array}{l}\text { A escola do poder explora a formação de estratégias como um processo de } \\
\text { negociação e barganha, ou seja, como um processo de influência, } \\
\text { enfatizando o uso do poder e da política (variáveis intangíveis) em seu } \\
\text { processo. Essa escola considera a variável política um sinônimo de uso do } \\
\text { poder, porém, não de maneira puramente econômica. Decorre daí que as } \\
\text { estratégias genéricas são oriundas de processos políticos. }\end{array}$ \\
\hline
\end{tabular}




\begin{tabular}{|c|c|c|}
\hline Escola & $\begin{array}{c}\text { Formulação } \\
\text { de estratégia } \\
\text { como processo }\end{array}$ & Descrição \\
\hline Cultural & Coletivo & $\begin{array}{l}\text { A principal premissa dessa escola é a ideia de que a formação da estratégia } \\
\text { é um processo fundamentalmente de interação social, que, por meio da } \\
\text { aculturação, gera conhecimento tácito, de modo que o conhecimento não } \\
\text { codificável acumulado é mais importante e determinante nos rumos das } \\
\text { organizações do que o proveniente do planejamento racional e deliberado. } \\
\text { A estratégia derivaria, portanto, de intenções coletivas que podem se } \\
\text { traduzir em barreiras e/ou facilitadores para determinadas escolhas. A } \\
\text { escola vê a formação das estratégias como um processo deliberadamente } \\
\text { emergente, trazendo a importante dimensão coletivista de um processo } \\
\text { social, embora não discutindo em sua implementação. }\end{array}$ \\
\hline Ambiental & Reativo & $\begin{array}{l}\text { Autores dessa escola consideram as organizações passivas, podendo apenas } \\
\text { reagir às mudanças em seu ambiente. Nesse caso, o ambiente ocupa, } \\
\text { mesmo que pontualmente, papel preponderante no processo de formação } \\
\text { estratégica, junto da liderança e da organização, assim, condicionado às } \\
\text { opções. Cabe à liderança a interpretação do ambiente de modo a garantir } \\
\text { uma adaptação adequada da organização. }\end{array}$ \\
\hline \multicolumn{3}{|r|}{ Escola Configurativa } \\
\hline Configuração & Transformador & $\begin{array}{l}\text { Caracterizada por sua dimensão abrangente, estabelece que para cada } \\
\text { período ou contexto a organização deveria adotar uma determinada } \\
\text { estrutura de formação de estratégias. A alternância entre períodos estáveis } \\
\text { e de mudança ensejaria a configuração da estratégia adequada, sendo cada } \\
\text { configuração explicada, em um dado momento, por uma das escolas } \\
\text { anteriores. }\end{array}$ \\
\hline
\end{tabular}

Fonte: Mintizberg, Ahlstrand e Lampel (2000)

Certamente, as estratégias empresariais não são estanques, e por isso, acabam mesclando em suas práticas visões de diferentes escolas de pensamento estratégico. Adicionalmente, Pelaez e Szmrecsányi (2006) e Kim e Mauborgne (2005) destacam a importância da inovação na formulação, implantação e gestão da estratégia organizacional.

Agregando agora um novo elemento neste cenário, Morgan e Strong (2003) sublinham a estreita relação entre estratégia e desempenho. Para Pun e White (2005) as organizações empregam variadas formas de avaliar sua performance, com destaque para os indicadores numéricos ou quantitativos destinados a estabelecer metas, padrões e objetivos para melhorar o desempenho organizacional.

A avaliação do desempenho de uma organização deixou de ser apenas observado pelos resultados financeiros, que não são suficientes para garantir que suas estratégias, objetivos e metas estão sendo alcançadas de forma sistêmica e global, como afirmam Quintella e Lima (2005).

Para o presente trabalho, avaliação de desempenho é definida conforme segue (ENSSLIN et al, 2010a, p. 130):

Avaliação de desempenho é o processo para construir conhecimento no decisor, a respeito do contexto especifico que se propõe avaliar, a partir da percepção do próprio decisor por meio de atividades que identifiquem, organizem, mensurem ordinalmente e cardinalmente, e sua integração e os meios para visualizar o impacto das ações e seu gerenciamento.

Para a organização, o processo de identificação das necessidades das partes interessadas é fundamental, como base para a definição de suas estratégias e planos que, por sua vez, irão definir 
as práticas de gestão e os processos operacionais destinados a este fim. Desta forma, a definição de um sistema de indicadores de desempenho vem a ser a ferramenta que permitirá traduzir a estratégia da empresa em objetivos e metas (QUINTELLA e LIMA. 2005).

A avaliação de desempenho vem despertando um crescente interesse, tanto por parte da indústria quanto da comunidade acadêmica, sendo considerado um elemento essencial para o gerenciamento das empresas. Vários motivos têm feito com que a avaliação do desempenho tenha angariado o interesse da comunidade de negócios, dentre eles, a mudança na natureza dos negócios, a competitividade cada vez mais acirrada, as novas iniciativas de melhoramento em operações e a mudança nas demandas externas (SILVA, LIMA e COSTA, 2009).

Este breve aporte teórico sobre gestão estratégica organizacional e avaliação de desempenho evidencia a abrangência e complexidade desses eixos de pesquisa, situação que denota a dificuldade de se principiar um estudo relacionado a esta temática. A esta constatação associa-se uma dificuldade adicional, relacionada à amplitude e dispersão do conhecimento em uma variedade de publicações, editores e bases de dados, motivo pelo qual, a identificação de estudos relacionados a um determinado tema de pesquisa, relevantes do ponto de vista científico e alinhamento com os objetivos dos pesquisadores que empreendem este trabalho, se configura em uma tarefa árdua e complexa (TASCA et al, 2010).

Neste sentido, Tasca et al (2010) evidenciam a problemática que muitos pesquisadores enfrentam ao tentar justificar o referencial teórico selecionado para sustentar as suas pesquisas. Situação que, segundo os autores, denota a relevância da utilização de um processo estruturado para este fim, no sentido de prover um quadro teórico robusto.

Diante deste contexto, emerge o problema de pesquisa que orienta a realização do presente artigo: Como construir o conhecimento demandado por um pesquisador quando do início de uma pesquisa no tema gestão estratégica organizacional com foco nos resultados, segundo a percepção de seu gestor, a fim de propiciar-lhe as condições necessárias para, em um segundo momento, buscar as oportunidades para contribuir na temática escolhida?

E para responder esta questão de pesquisa, este trabalho tem como objetivo geral construir, no pesquisador, o conhecimento necessário para orientá-lo onde buscar as oportunidades (lacunas) para pesquisar sobre o tema gestão estratégica sob o enfoque da avaliação de desempenho.

O alcance deste objetivo geral será possível por meio dos seguintes objetivos específicos: (i) Selecionar um Portfólio Bibliográfico relevante sobre a gestão estratégica sob o viés da avaliação de desempenho, e (ii) Realizar análise bibliométrica do portfólio bibliográfico selecionado e de suas referências, visando identificar os periódicos, artigos, autores e palavras-chave de destaque.

Sendo a gestão estratégica organizacional o objeto de estudo central deste artigo, este tema passa a ser considerado o primeiro eixo desta pesquisa. Ao abordar este assunto pela perspectiva de 
seus resultados, surge a demanda de vê-lo sob o espectro da avaliação de desempenho, portanto, o segundo eixo de pesquisa deste trabalho.

Para a consecução de seus objetivos, este artigo segue apresentado em cinco seções, sendo a primeira composta pela introdução, a segunda pelos procedimentos metodológicos da pesquisa, a terceira pelo processo de seleção do portfólio bibiográfico para o presente tema, a quarta pela análise bibliométrica do portfólio bibliográfico selecionado e, finalmente, a quinta seção evidencia as conclusões da pesquisa empreendida.

\section{Procedimentos metodológicos}

Os procedimentos metodológicos desta pesquisa classificam-se de acordo com a Figura 1.

Esta é uma pesquisa descritiva, pois relata com exatidão os fenômenos da realidade estudada. Para Gil (1999), este tipo de pesquisa objetiva descrever as características de determinada população e o estabelecimento de relações entre as variáveis, procurando mostrar a frequência com que o fenômeno ocorre, ou a relação e conexão com outros, sua natureza e características.

A pesquisa também é exploratória, tendo em vista que proporciona uma maior familiaridade com o problema, no sentido de torná-lo explicito ou permitir a construção de hipóteses (GIL, 1999).

Em relação ao quesito abordagem, o presente trabalho enquadra-se como uma pesquisa qualitativa, conforme asseveram Minayo, Delandes e Gomes (2007), já que corresponde a questões muito particulares, onde não se consegue quantificar. Esta trabalha com o universo dos significados, dos motivos, das aspirações, das crenças, dos valores e atitudes. E também como uma pesquisa quantitativa, a partir do momento em que é determinada em relação aos dados ou à proporção numérica (FACHIN, 2005).

Em relação aos procedimentos técnicos esta pesquisa enquadra-se, dentro da classificação de Gil (1999), como uma pesquisa bibliográfica e pesquisa-ação, por ser elaborada a partir de material publicado anteriormente, principalmente periódicos científicos. Lakatos e Marconi (2006), afirmam que a pesquisa bibliográfica consiste em um apanhado geral sobre os principais trabalhos de grande importância já realizados e disponibilizados. Por sua vez, a pesquisa-ação é empregada considerando que o pesquisador interage durante todo o processo com o objeto de pesquisa.

De acordo com Tasca et al (2010) o processo de pesquisa cientifica inicia-se com o delineamento do problema de pesquisa, perguntas ou dúvidas, que faz com que os pesquisadores investiguem e procurem informações sobre um dado assunto em bibliotecas e bases bibliográficas digitais. 
Figura 1 - Enquadramento metodológico

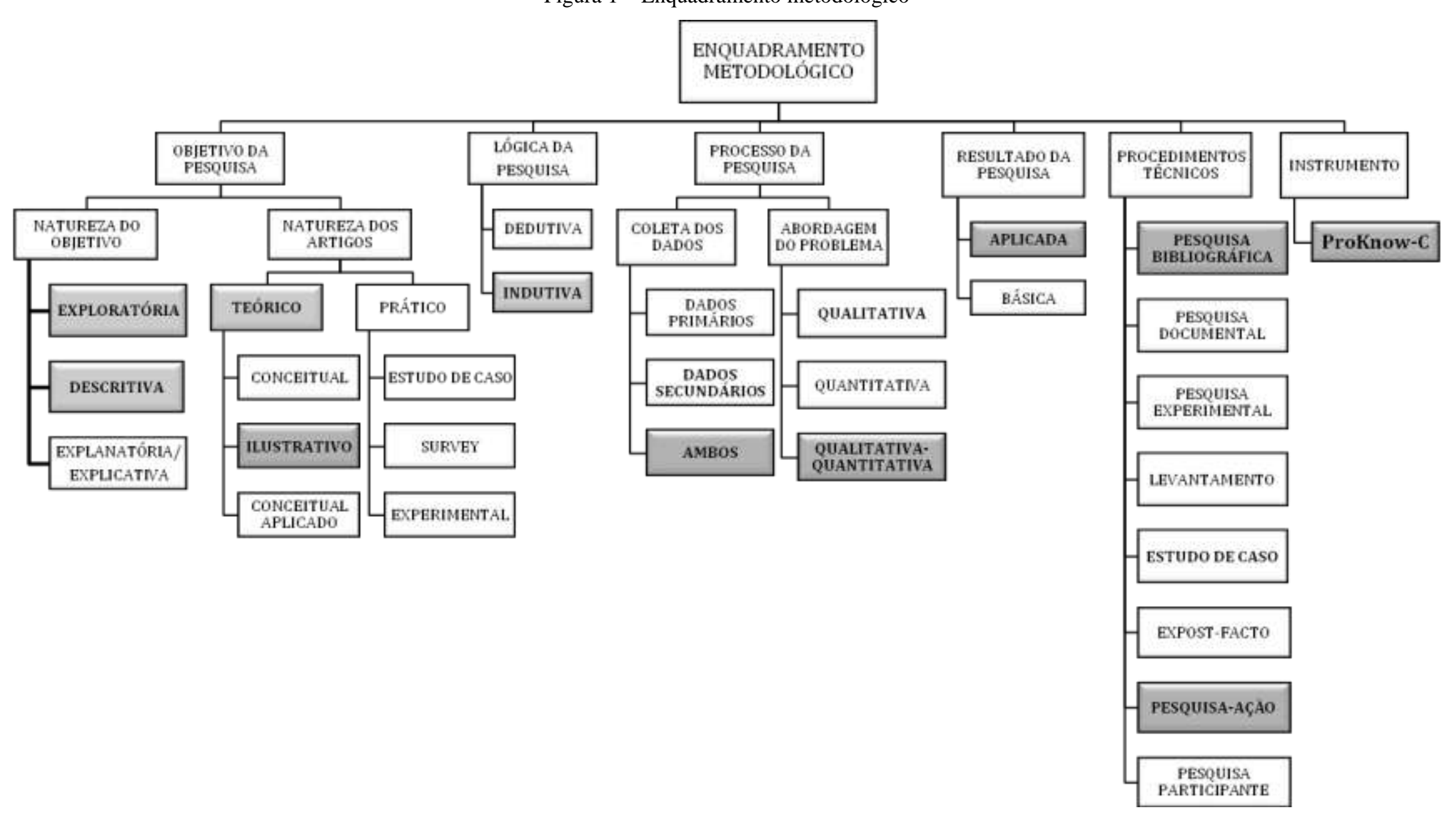

Fonte: Adaptado de Tasca et al (2010) 
Lacerda, Ensslin, Ensslin (2011), em complemento, afirma que a evolução dos sistemas de informações e o uso de base de dados (sistemas indexados), procuram facilitar as buscas pelas referências bibliográficas, e servem de plataformas teóricas para pesquisas futuras. Diante deste contexto, optou-se por utilizar como instrumento de intervenção neste trabalho o processo para revisão bibliográfica segundo a visão construtivista, denominado ProKnow-C - Knowledge Development Process - Constructivist (ENSSLIN et al, 2010b).

O instrumento de intervenção proposto por Ensslin et al (2010b) para a seleção de um portfólio bibliográfico está consubstanciado em um processo subdividido em quatro fases: (a) seleção do banco de artigos brutos (Figura 2): composto pela definição das palavras-chave, definição dos bancos de dados, busca de artigos nos bancos de dados com as palavras-chave e o teste da aderência das palavras-chave; (b) filtragem inicial (Figura 3): integrada pela filtragem do banco de artigos brutos quanto à redundância e filtragem do banco de artigos brutos não repetidos quanto ao alinhamento do título; (c) filtragem principal do banco de artigos (Figura 4): composto pela determinação do reconhecimento científico dos artigos e o alinhamento dos artigos quanto ao resumo; (d) filtragem quanto ao alinhamento do artigo integral (Figura 5): composto pela leitura integral dos artigos.

Selecionado o portfólio bibliográfico, também por meio do ProKnow-C, o presente artigo procederá a análise bibliométrica dos artigos que o compõe. A análise bibliométrica é uma técnica para o mapeamento dos principais autores, periódicos e palavras-chave sobre determinado tema. Maldonado, Silva Santos e Santos (2010) afirmam que essas técnicas constituem ferramentas que se apoiam em uma base teórico-metodológica reconhecida cientificamente, que possibilita o uso de métodos estatísticos e matemáticos para mapear informações, a partir de registros bibliográficos de documentos armazenados em bases de dados.

Adicionalmente, destaca-se a definição de análise bibliométrica apresentada por Ensslin et al (2010b, p. 2):

É o processo de evidenciação quantitativa dos dados estatísticos de um conjunto definido de artigos (portfólio bibliográfico) para a gestão da informação e do conhecimento cientifico de um dado assunto, realizado por meio da contagem de documentos.

Para a análise bibliométrica são utilizados os artigos constantes do portfólio bibliográfico e suas referências, visando apurar o grau de relevância de periódicos, o grau de reconhecimento científico de artigos, o grau de relevância dos autores e as palavras-chave mais utilizadas, consoante detalhamento apresentado nas Figuras 6 e 7.

Destaca-se, oportunamente, que todos os procedimentos descritos neste trabalho foram realizados no mês de março do ano de 2011. 
Figura 2 - Seleção do banco de artigos brutos

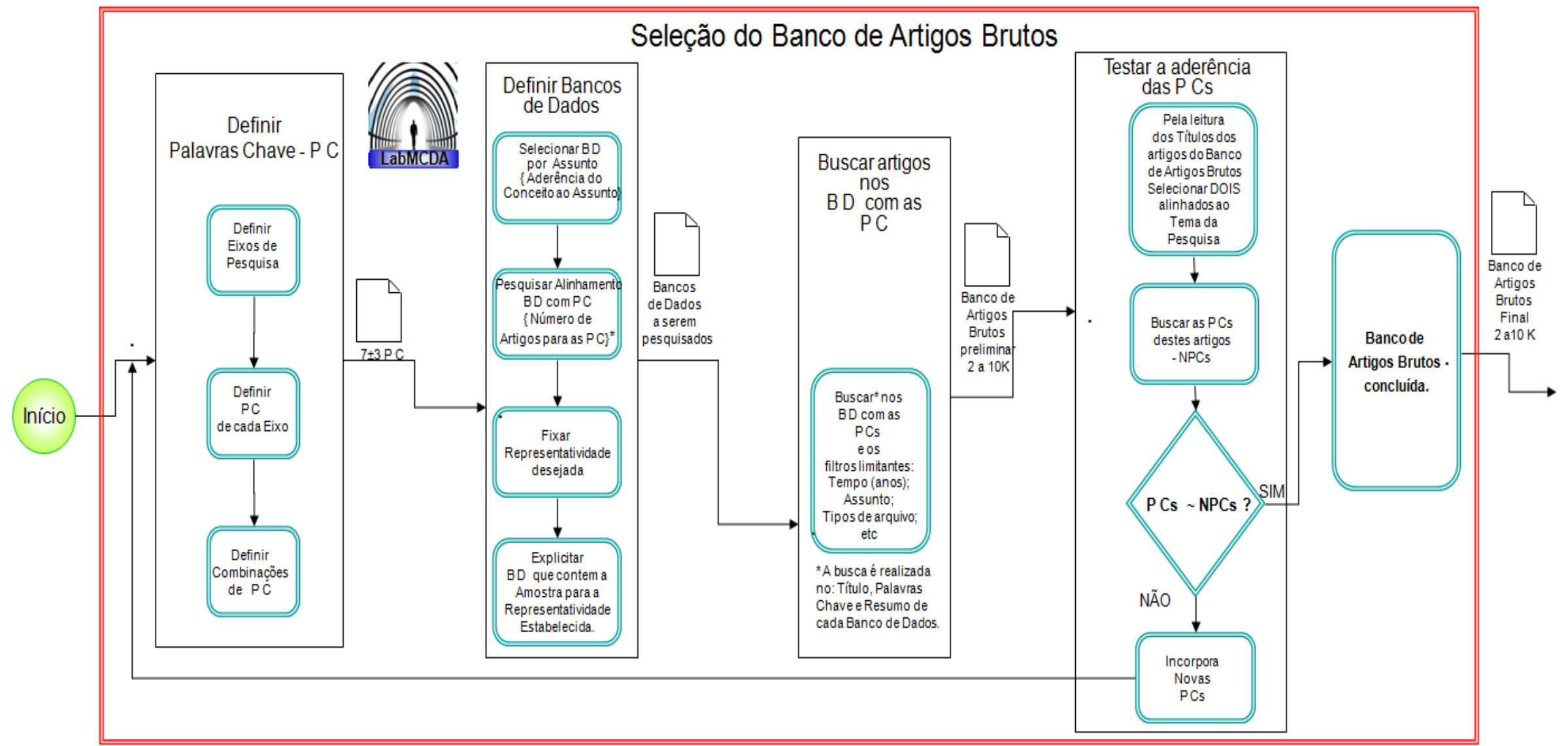

Fonte: Ensslin et al (2010) 
Figura 3 - Filtragem inicial

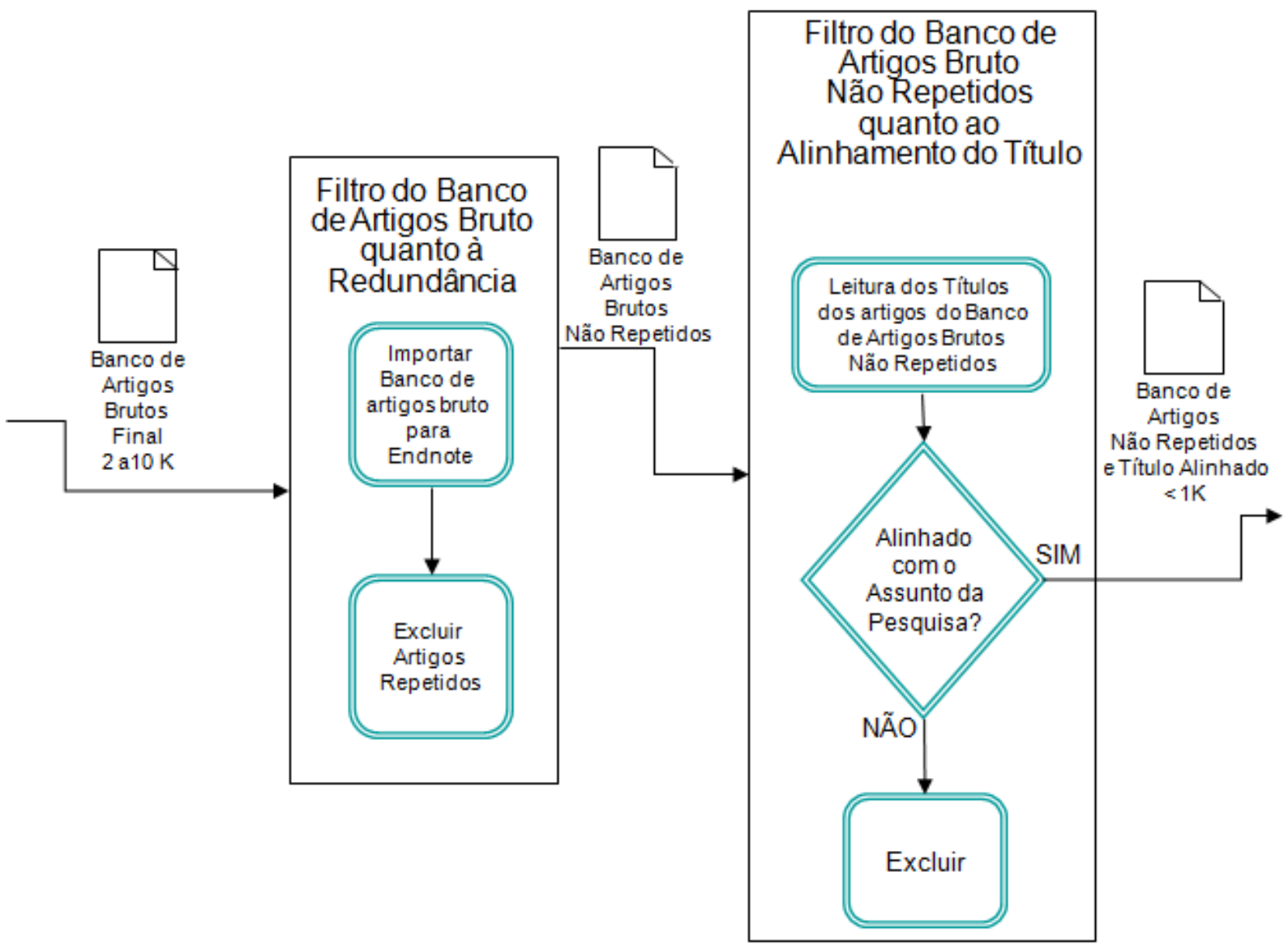

Fonte: Ensslin et al (2010) 
Figura 4 - Filtragem principal do banco de artigos

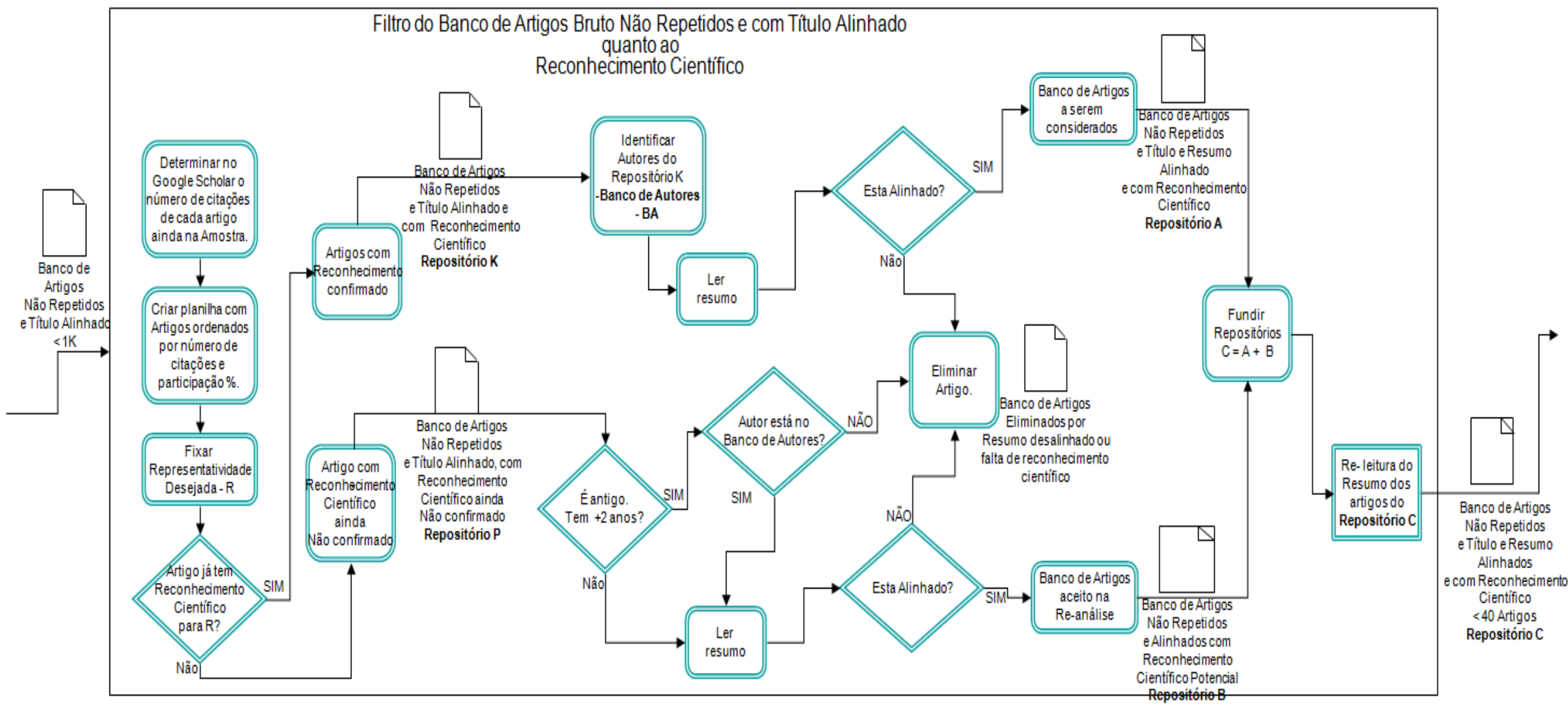

Fonte: Ensslin et al (2010) 
Figura 5 - Filtragem quanto ao alinhamento do artigo integral

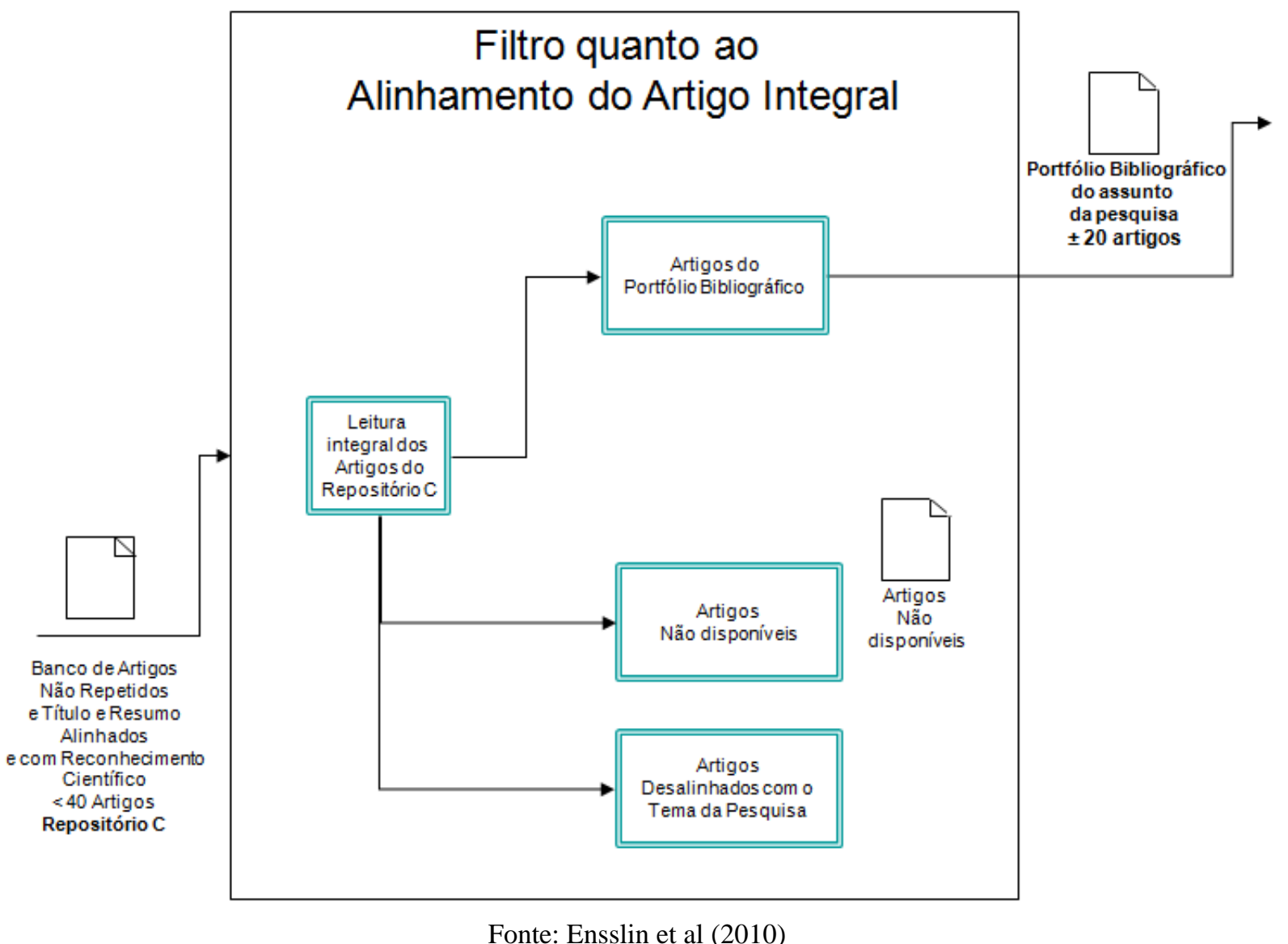


Figura 6 - Análise Bibliométrica - Origem dos Dados

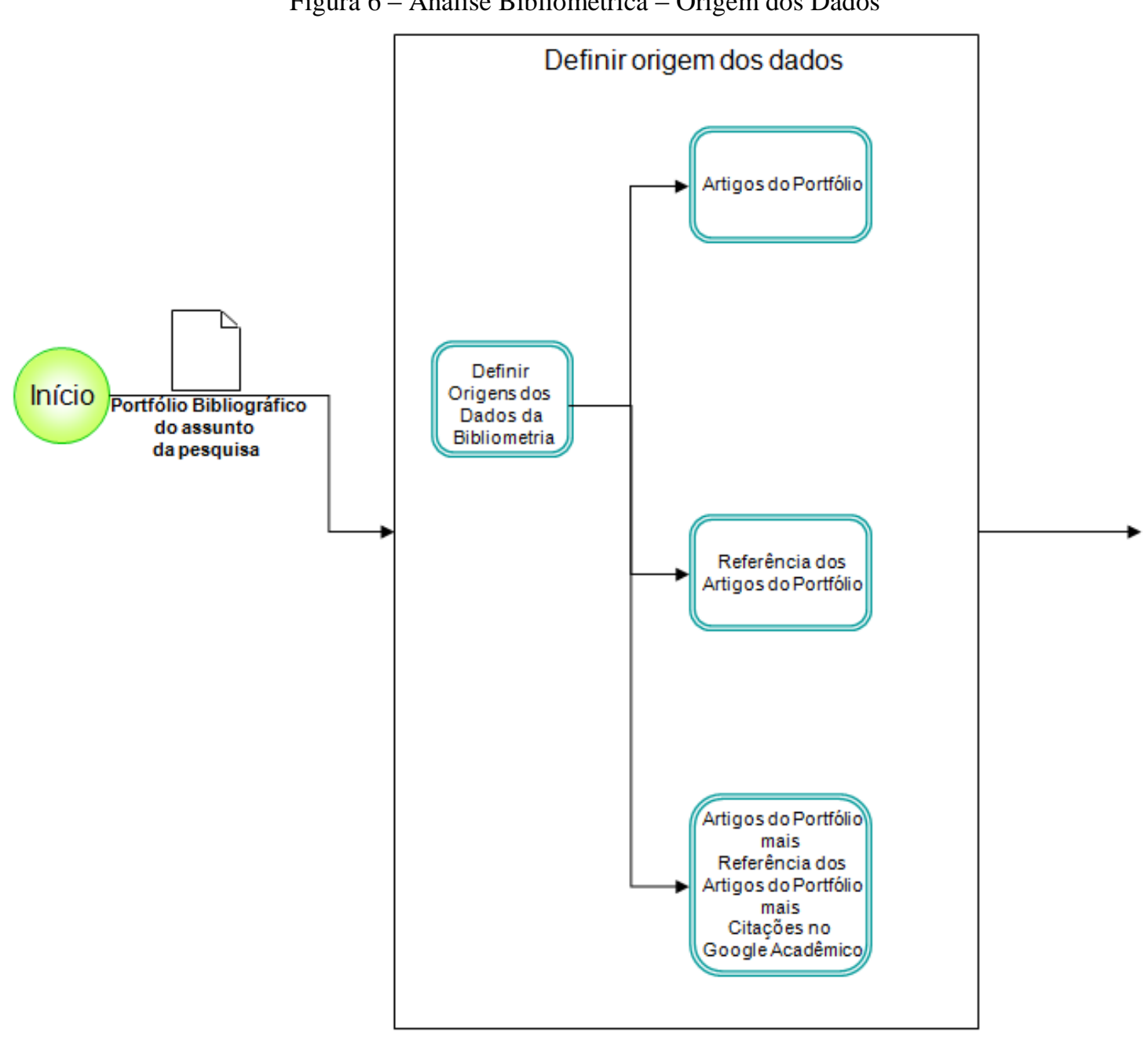

Fonte: Ensslin et al (2010) 
Figura 7 - Análise Bibliométrica - Análises realizadas
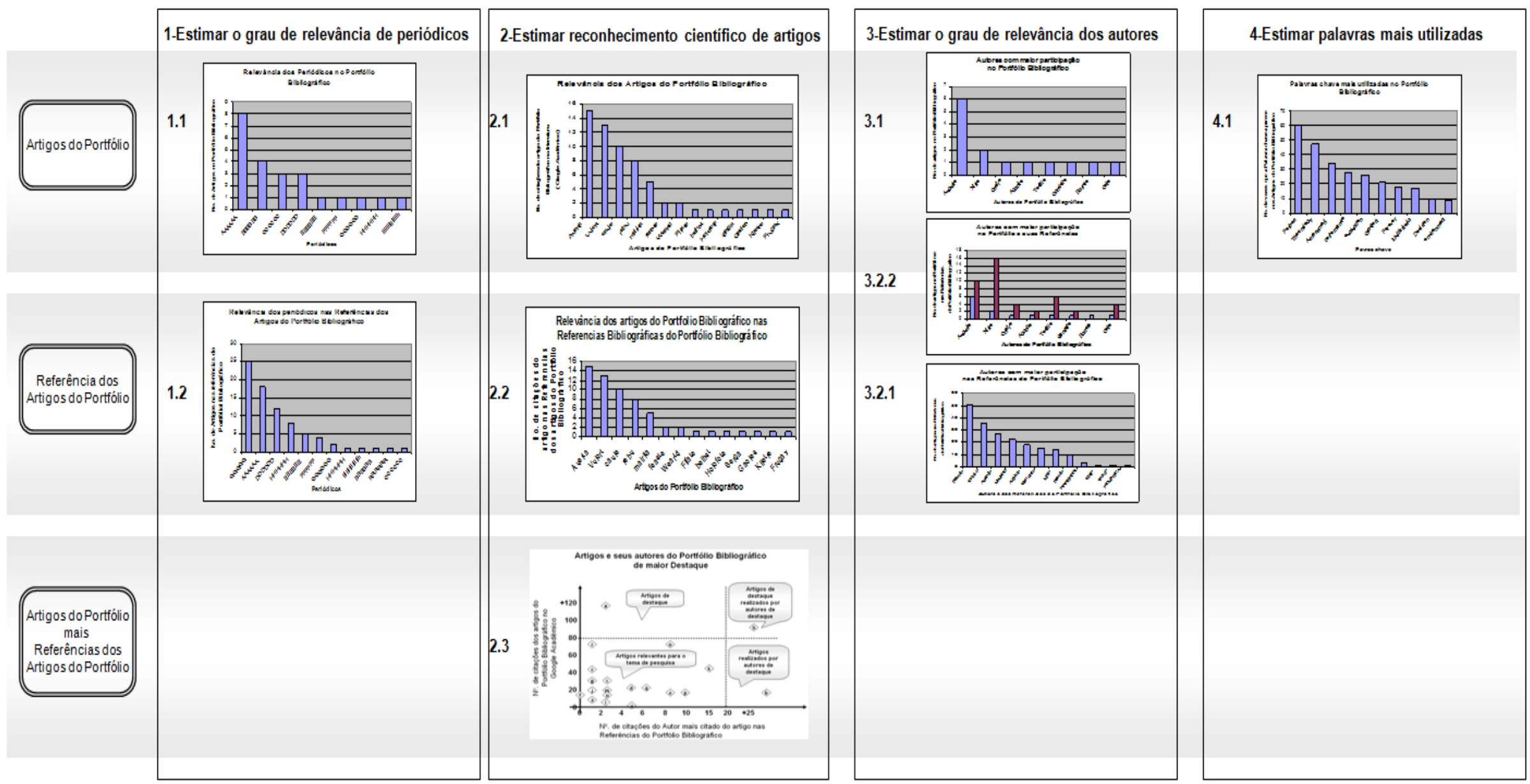

Fonte: Ensslin et al. (2010) 


\section{Seleção do referencial teórico de pesquisa ou construção do portfólio bibliográfico}

Nesta seção, e na subsequente, serão apresentados os resultados da aplicação do ProKnow-C para o presente contexto de pesquisa.

Para tanto, esta seção, destinada a evidenciar como foi selecionado o referencial teórico sobre gestão estratégica organizacional pelo viés da avaliação de desempenho, foi dividida em três subseções: 3.1 Seleção do banco de artigos brutos; 3.2 Filtragens do banco de artigos brutos; 3.3 Filtragem quanto ao alinhamento do artigo integral.

\subsection{Seleção do banco de artigos brutos}

Esta subseção está dividida em 3.1.1 Definição das palavras-chave e 3.1.2 Definição das bases de dados.

\subsubsection{Definição das palavras-chave}

Como destacado na introdução deste artigo, a presente pesquisa está alicerçada em dois eixos de pesquisa. Neste sentido, a definição das palavras-chave que foram utilizadas para a seleção dos artigos brutos respeitou este parâmetro, sendo que o primeiro eixo trouxe as palavras-chave relacionadas à Gestão Estratégica Organizacional, e o segundo, ao tema Avaliação de Desempenho (Quadro 1).

Quadro 1 - Apresentação das palavras-chave

\begin{tabular}{|c|c|}
\hline GESTÃO ESTRATÉGICA ORGANIZACIONAL & AVALIAÇÃO DE DESEMPENHO \\
\hline Strategic Management & Performance Measurement \\
\hline Corporate Strategy & Performance Appraisal \\
\hline Strategic Planning & Performance Assessment \\
\hline Strategy-focused Organization & Performance Evaluation \\
\hline
\end{tabular}

Fonte: Autoria própria (2012)

Para a consecução da pesquisa, no sentido de buscar artigos alinhados com o tema de gestão estratégica organizacional sob o enfoque da avaliação de desempenho, as palavras-chave dos dois eixos de pesquisa foram combinadas conforme demonstrado nas Figuras 8, 9, 10 e 11. 
Figura 8 - Combinação com Performance Assessment

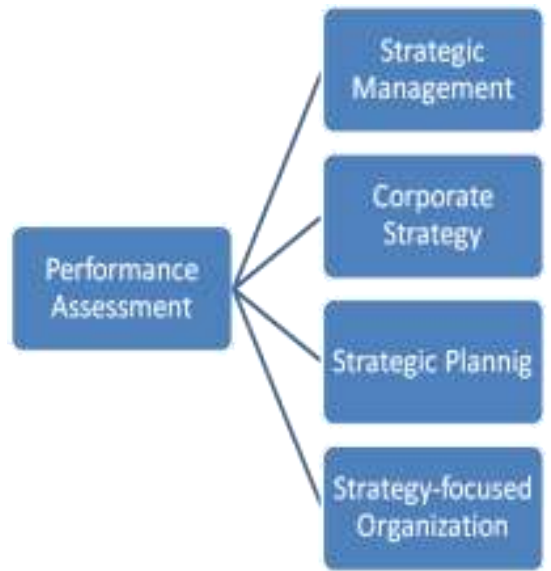

Fonte: Autoria própria (2012)

Figura 10 - Combinação com Performance

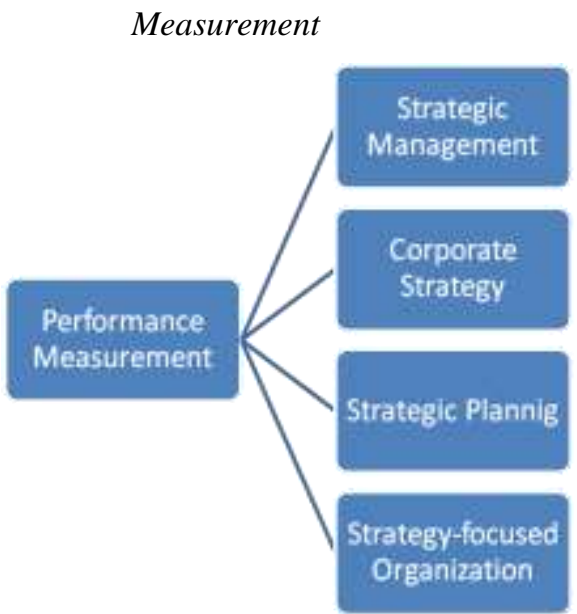

Fonte: Autoria própria (2012)
Figura 9 - Combinação com Performance Evaluation

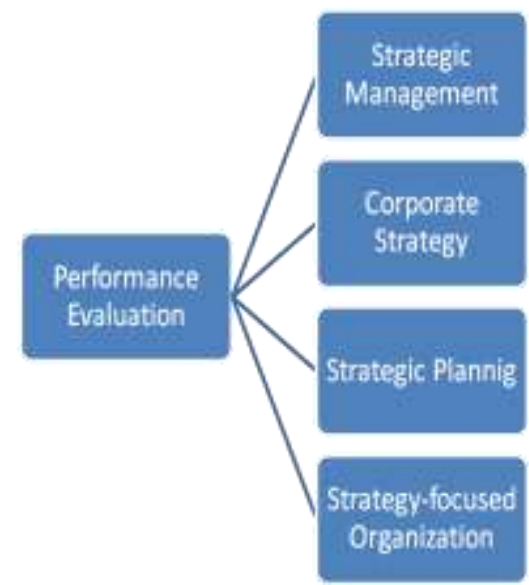

Fonte: Autoria própria (2012)

Figura 11 - Combinação com Performance Appraisal

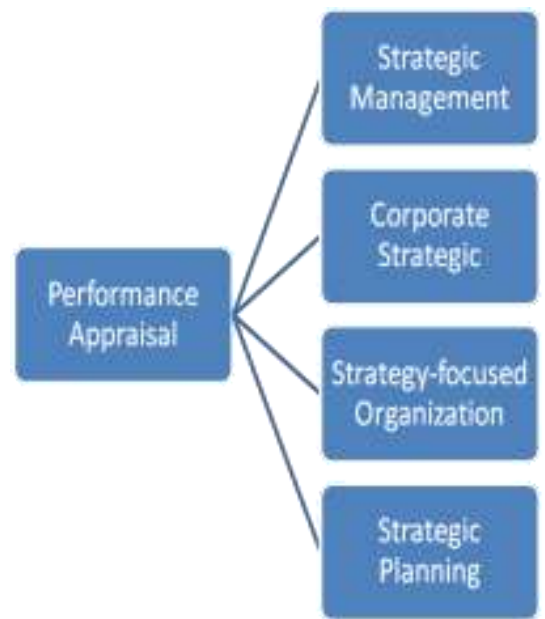

Fonte: Autoria própria (2012)

Após a definição das bases de dados, cujo detalhamento segue na próxima subseção, e da seleção do banco de artigos brutos, foram identificados dois artigos aderentes ao tema de pesquisa e analisadas as palavras-chave utilizadas pelos autores para representar o assunto abordado em seus respectivos trabalhos, no sentido de validar as palavras-chave definidas para a presente pesquisa ou apontar a necessidade de alteração dessas palavras-chave ou agregação de novas. Foram analisados os seguintes artigos:

- Base SCOPUS: LOHMAN, C.; FORTUIN, L.; WOUTERS, M. Designing a performance measurement system: a case study. European Journal of Operational Research, vol. 156, n. 2, p. 267-286, 2004. Palavras-chave - Performance Measurement, Balanced Scorecard, Supply Chain Management;

- Base Science Direct: CRAVENS, K. S.; OLIVER, E. G.; STEWART, J. S. Can a positive approach to performance evaluation help accomphish your goals? Business Horizons, vol. 53, n. 3, 
p. 269-279, 2010. Palavras-chave - Performance Evaluation, Performance Measures, Positive Organization Scholarship, Balanced Scorecard.

Pode-se observar por esta análise, que as palavras-chave escolhidas para o presente trabalho eram adequadas e suficientes para representar o tema objeto da pesquisa.

\subsubsection{Definição das bases de dados}

Definidas as palavras-chave, iniciou-se o processo de seleção das bases de dados com acesso via internet que indexam periódicos. Foram analisadas as bases de dados de editores com acesso viabilizado pela Coordenação de Aperfeiçoamento de Pessoal de Nível Superior - CAPES, por meio de seu portal de periódicos (CAPES, 2011). Para a seleção das bases de dados alinhadas ao tema do presente estudo, foram consideradas aquelas bases relacionadas as areas de ciências sociais aplicadas, engenharias e multidiciplinar, perfazendo um total de 90 bases, a saber:

- Multidiciplinar: 19 bases;

- Engenharias: 33 bases;

- Ciências Sociais Aplicadas: 36 bases.

Destas, após a leitura da descrição de cada uma das bases de dados, 13 aparentavam ter maior afinidade com o objeto deste estudo, sendo elas:

- Scopus;

- ScienceDirect (Elsevier);

- Emerald Fulltext (Emerald);

- Project Muse;

- Wiley Online Library;

- JSTOR Arts \& Sciences I Collection;

- Highwire Press;

- Web of Science;

- SpringerLink (MetaPress);

- ACM Digital Library;

- Academic Search Premier - ASP (EBSCO);

- Oxford Journals (Oxford University Press);

- Cambridge Journals Online.

Desta forma, foi realizada a pesquisa com o conjunto de palavras-chave em cada uma das 13 bases de dados, atividade que permitiu selecionar as quatro bases mais relevantes em relação ao tema, ou seja, com maior representatividade:

- Web of science: base multidisciplinar que indexa somente os periódicos mais citados em suas respectivas áreas. É também um índice de citações, informando, para cada artigo, os 
documentos por ele citados e os documentos que o citaram. Possuía à época da pesquisa mais de 9.000 periódicos indexados.

- Scopus: base de dados de resumos e de citações da literatura científica e de fontes de informação de nível acadêmico na Internet. Indexa mais de 15 mil periódicos, cerca de 265 milhões páginas da Internet, 18 milhões de patentes, além de outros documentos.

- Emerald: coleção de publicações periódicas com concentração nas áreas de Administração, Contabilidade, Ciência da Informação, Engenharia Mecânica, Enegenharia Elétrica e Engenharia de Produção.

- Science Direct: estão disponíveis publicações da Elsevier e de outras editoras científicas, cobrindo as áreas de Ciências Biológicas, Ciências da Saúde, Ciências Agrárias, Ciências Exatas e da Terra, Engenharias, Ciências Sociais Aplicadas, Ciências Humanas e Letras e Artes.

A quantidade total de artigos encontrados nestas quatro bases de dados, consoante as combinações de palavras-chave e a delimitação temporal de 10 anos (2001 a 2011) foi de 12.915 artigos, distribuídos conforme evidenciado no Gráfico 1. Este conjunto de artigos passou a compor o banco de artigos brutos.

Da análise do Gráfico 1, destaca-se a forte aderência ao tema desta pesquisa das bases de dados Science Direct e Emerald.

\subsection{Filtragens do banco de artigos brutos}

A presente subseção está dividida em 3.2.1 Filtragem do banco de artigos bruto quanto à redundância e 3.2.2 Filtragem do banco de artigos bruto não repetido quanto ao alinhamento do título.

Gráfico 1 - Quantidade de artigos por bases

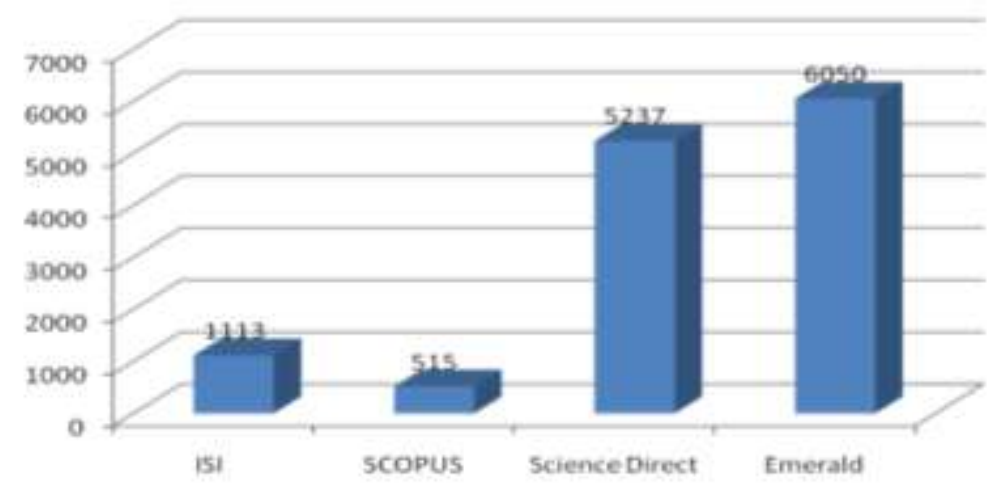

Fonte: Autoria própria (2012)

\subsubsection{Filtragem do banco de artigos bruto quanto à redundância}

O banco de dados de publicações obtidas por meio das combinações de palavras-chave empregadas foi composto por 12.915 documentos advindos das bases Web of science, Emerald, Science Direct e Scopus - as mais representativas para o presente contexto de pesquisa. 
Para iniciar o processo de filtragem do banco de artigos bruto quanto à redundância, as referências destas 12.915 publicações foram exportadas para o gerenciador de referências bibliográficas Endnote.

Considerando que muitas vezes os artigos podem estar postados em mais de uma base ou relacionados a mais de uma combinação de palavras-chave, bem como pode haver na amostra outros tipos de publicações, tais como livros, projetos, patentes, etc., foi realizada a verificação de artigos duplicados e a análise do tipo de documento, haja vista que o que se desejava obter era artigos publicados em periódicos científicos. Esta ação resultou na exclusão de 7.267 documentos duplicados ou que não eram artigos científicos.

\subsubsection{Filtragem do banco de artigos bruto não repetido quanto ao alinhamento do título}

A filtragem do banco de artigos bruto não repetido quanto ao alinhamento do título direciona o pesquisador, agora, para a leitura dos títulos dos artigos da amostra.

O objetivo desta etapa reside na verificação do alinhamento dos títulos dos artigos com o tema da pesquisa.

Diante disso, a leitura dos títulos dos 5.658 artigos não repetidos, permitiu a seleção de 251 artigos alinhados com o tema gestão estratégica organizacional pela perspectiva da avaliação de desempenho.

\subsection{Filtragem do banco de artigos e alinhamento integral dos artigos}

A filtragem do banco de artigos principia pela verificação do reconhecimento científico, apurado por meio do número de citações dos artigos no Google Scholar (GOOGLE, 2011).

Diante deste direcionamento, foi identificado o número de citações dos 251 artigos, estabelecendo-se que seriam considerados com reconhecimento científico confirmado aqueles artigos que estivessem dentro do percentual de $85 \%$ de participação no total de citações da amostra.

Foram selecionados 61 artigos que apresentaram o número de citações dentro do percentual de $85 \%$.

A próxima etapa era constituída pela leitura dos resumos dos 61 artigos selecionados para verificação do alinhamento com o tema de pesquisa. Destes artigos com reconhecimento científico confirmado, apenas 11 artigos estavam alinhados com o tema e todos se apresentaram disponíveis no portal CAPES.

No entanto, antes de concluir esta filtragem, os 190 artigos eliminados pelo critério de reconhecimento científico foram reanalisados por dois critérios estipulados por Ensslin et al (2010b), sendo eles:

a) Artigos publicados a menos de dois anos da análise, dado que não tiveram tempo de serem repercutidos na comunidade científica e assim bem citados; e, 
b) Se publicados há mais de 2 anos, analisar se são de autoria de algum pesquisador já presente no grupo dos 61 artigos que tiveram a relevância acadêmica confirmada.

Por meio desses critérios de reanálise dos artigos menos citados, a amostra desse grupo restou consolidada com 03 artigos, que foram somados com os 11artigos anteriormente selecionados, perfazendo, agora, um total de 14 artigos.

Como procedimento final desta etapa de construção do portfólio, foi realizada a leitura integral dos 14 artigos, momento em que se verificou que destes, 12 artigos estavam efetivamente alinhados com a pesquisa em questão. O quadro 2 apresenta os artigos constante do portfólio bibliográfico desta pesquisa.

Quadro 2 - Artigos do portfólio bibliográfico

\begin{tabular}{|c|c|c|c|}
\hline ANO & AUTORES & TÍTULO & PERIÓDICO \\
\hline 2003 & $\begin{array}{l}\text { MORGAN, R. E. } \\
\text { STRONG, C. A. }\end{array}$ & $\begin{array}{l}\text { Business performance and dimensions of strategic } \\
\text { orientation. }\end{array}$ & $\begin{array}{l}\text { Journal of Business } \\
\text { Research }\end{array}$ \\
\hline 2003 & YENIYURT, S. & $\begin{array}{c}\text { A literature review and integrative performance } \\
\text { measurement framework for multinational } \\
\text { companies. }\end{array}$ & $\begin{array}{l}\text { Marketing Intelligence \& } \\
\text { Planning }\end{array}$ \\
\hline 2004 & $\begin{array}{l}\text { NANDAKUMAR, M. } \\
\text { K. GHOBADIAN, A } \\
\text { O'REGAN, N. }\end{array}$ & $\begin{array}{l}\text { Generic strategies and performance - Evidence } \\
\text { from manufacturing firms. }\end{array}$ & $\begin{array}{l}\text { International Journal of } \\
\text { Productivity and } \\
\text { Performance Management }\end{array}$ \\
\hline 2004 & $\begin{array}{l}\text { O'REGAN, N. } \\
\text { GHOBADIAN, A }\end{array}$ & $\begin{array}{c}\text { The importance of capabilities for strategic } \\
\text { direction and performance. }\end{array}$ & Management Decision \\
\hline 2005 & $\begin{array}{c}\text { BOURNE, } \mathrm{M} . \\
\text { KENNERLEY, } \mathrm{M} . \\
\text { FRANCO-SANTOS, M. }\end{array}$ & $\begin{array}{c}\text { Managing through measures: a study of impact } \\
\text { on performance. }\end{array}$ & $\begin{array}{l}\text { Journal of Manufacturing } \\
\text { Technology Management }\end{array}$ \\
\hline 2005 & $\begin{array}{l}\text { PUN, K. F. } \\
\text { WHITE, A. S. }\end{array}$ & $\begin{array}{c}\text { A performance measurement paradigm for } \\
\text { integrating strategy formulation: A review of } \\
\text { systems and frameworks. }\end{array}$ & $\begin{array}{l}\text { International Journal of } \\
\text { Management Reviews }\end{array}$ \\
\hline 2006 & $\begin{array}{l}\text { O'REGAN, N. } \\
\text { GHOBADIAN, A }\end{array}$ & $\begin{array}{c}\text { Perceptions of generic strategies of small and } \\
\text { medium sized engineering and electronics } \\
\text { manufacturers in the UK: The applicability of the } \\
\text { Miles and Snow typology. }\end{array}$ & $\begin{array}{l}\text { Journal of Manufacturing } \\
\text { Technology Management }\end{array}$ \\
\hline 2007 & $\begin{array}{c}\text { FRANCO-SANTOS, M. } \\
\text { KENNERLEY, M. } \\
\text { MICHELI, P. } \\
\text { MARTINEZ, V. } \\
\text { MASON, S. } \\
\text { MARR, B. } \\
\text { GRAY, D. } \\
\text { NEELY, A. }\end{array}$ & $\begin{array}{c}\text { Towards a definition of a business performance } \\
\text { measurement system. }\end{array}$ & $\begin{array}{l}\text { International Journal of } \\
\text { Operations \& Production } \\
\text { Management }\end{array}$ \\
\hline 2007 & $\begin{array}{l}\text { O'REGAN, N. } \\
\text { SIMS, M. A. } \\
\text { GALLEAR, D. }\end{array}$ & $\begin{array}{l}\text { Leaders, loungers, laggards: The strategic- } \\
\text { planning-environment- performance relationship } \\
\text { re-visited in manufacturing SMEs. }\end{array}$ & $\begin{array}{l}\text { Journal of Manufacturing } \\
\text { Technology Management }\end{array}$ \\
\hline 2008 & $\begin{array}{l}\text { CADEZ, S. } \\
\text { GUILDING, C. }\end{array}$ & $\begin{array}{c}\text { An exploratory investigation of an integrated } \\
\text { contingency model of strategic management } \\
\text { accounting. }\end{array}$ & $\begin{array}{c}\text { Accounting Organizations } \\
\text { and Society }\end{array}$ \\
\hline 2009 & $\begin{array}{l}\text { MICHAEL, J. } \\
\text { McCARTY, T. } \\
\text { VELO, B. }\end{array}$ & $\begin{array}{c}\text { Performance measurement in corporate real } \\
\text { estate. }\end{array}$ & $\begin{array}{c}\text { Journal of Corporate Real } \\
\text { Estate }\end{array}$ \\
\hline 2010 & $\begin{array}{l}\text { MICHELI, P. } \\
\text { MANZONI, J.-F. }\end{array}$ & $\begin{array}{l}\text { Strategic performance measurement: Benefits, } \\
\text { limitations and paradoxes. }\end{array}$ & Long Range Planning \\
\hline
\end{tabular}

Fonte: Autoria própria (2012) 


\section{Análise bibliométrica}

Para análise bibliométrica do portfólio bibliográfico sobre a gestão estratégica organizacional pela perspectiva da avaliação de desempenho, seguiu-se a aplicação do ProKnow-C, desenvolvido nesta dimensão em três etapas, que serão descritas e detalhadas nas seguintes subseções: 4.1 Análise bibliométrica dos artigos selecionados; 4.2 Análise bibliométrica das referências dos artigos selecionados; e, 4.3 Classificação dos artigos por sua relevância acadêmica na amostra.

\subsection{Análise bibliométrica dos artigos selecionados}

A análise bibliométrica, tendo como origem dos dados os artigos do portfólio bibliográfico, buscou apurar, primeiramente, o número de artigos por periódicos, composta pelo número de artigos em um determinado periódico (Gráfico 2).

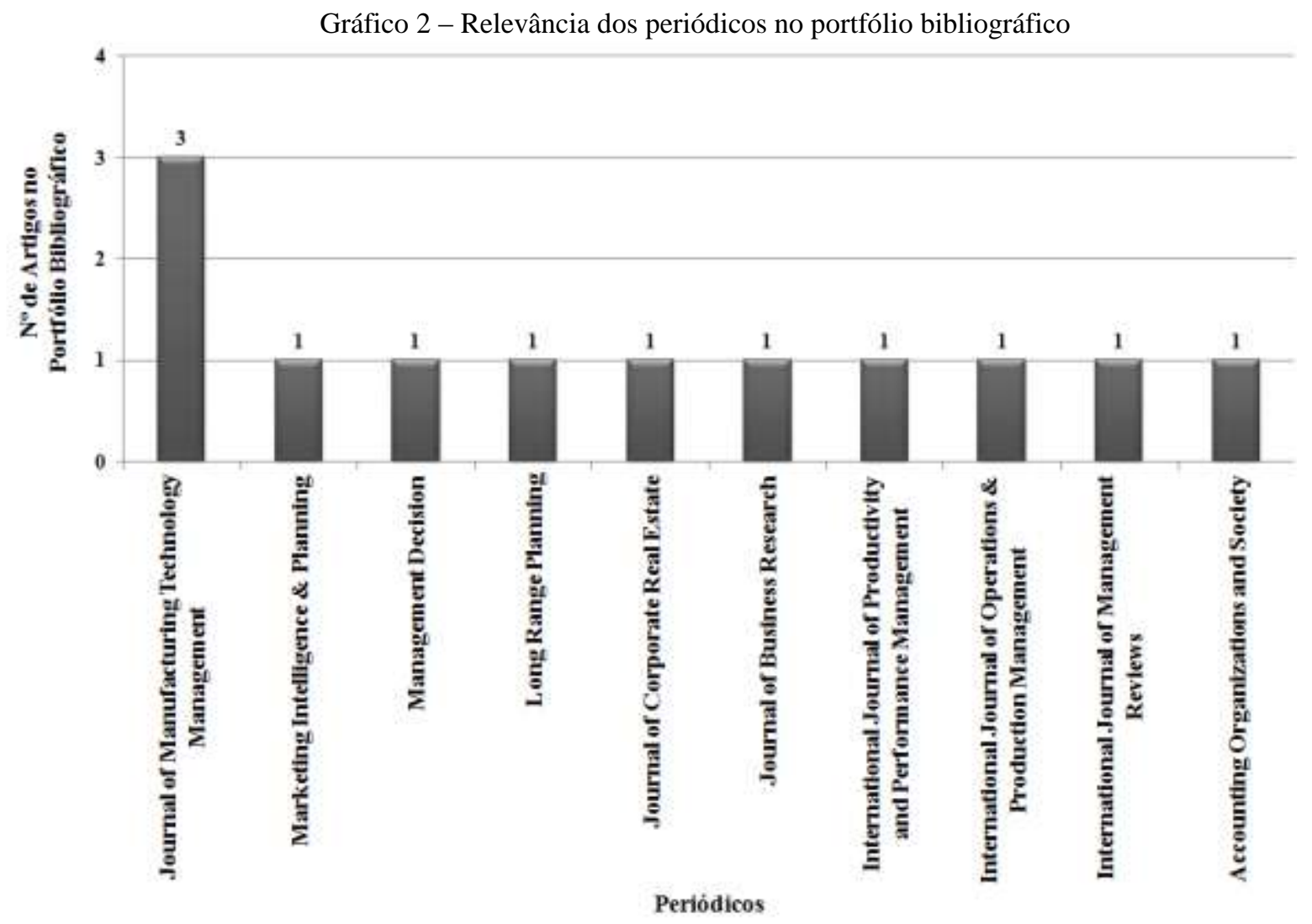

Fonte: Autoria própria (2012)

Dos 12 artigos selecionados no portfólio bibliográfico, 03 foram publicados no Journal of Manufacturing Technologyc Management.

Já a análise do reconhecimento científico dos artigos pelo número de citações no Google Scholar (GOOGLE, 2011), segue apresentada no Gráfico 3. 
Gráfico 3 - Relevância dos artigos no Portfólio Bibliográfico

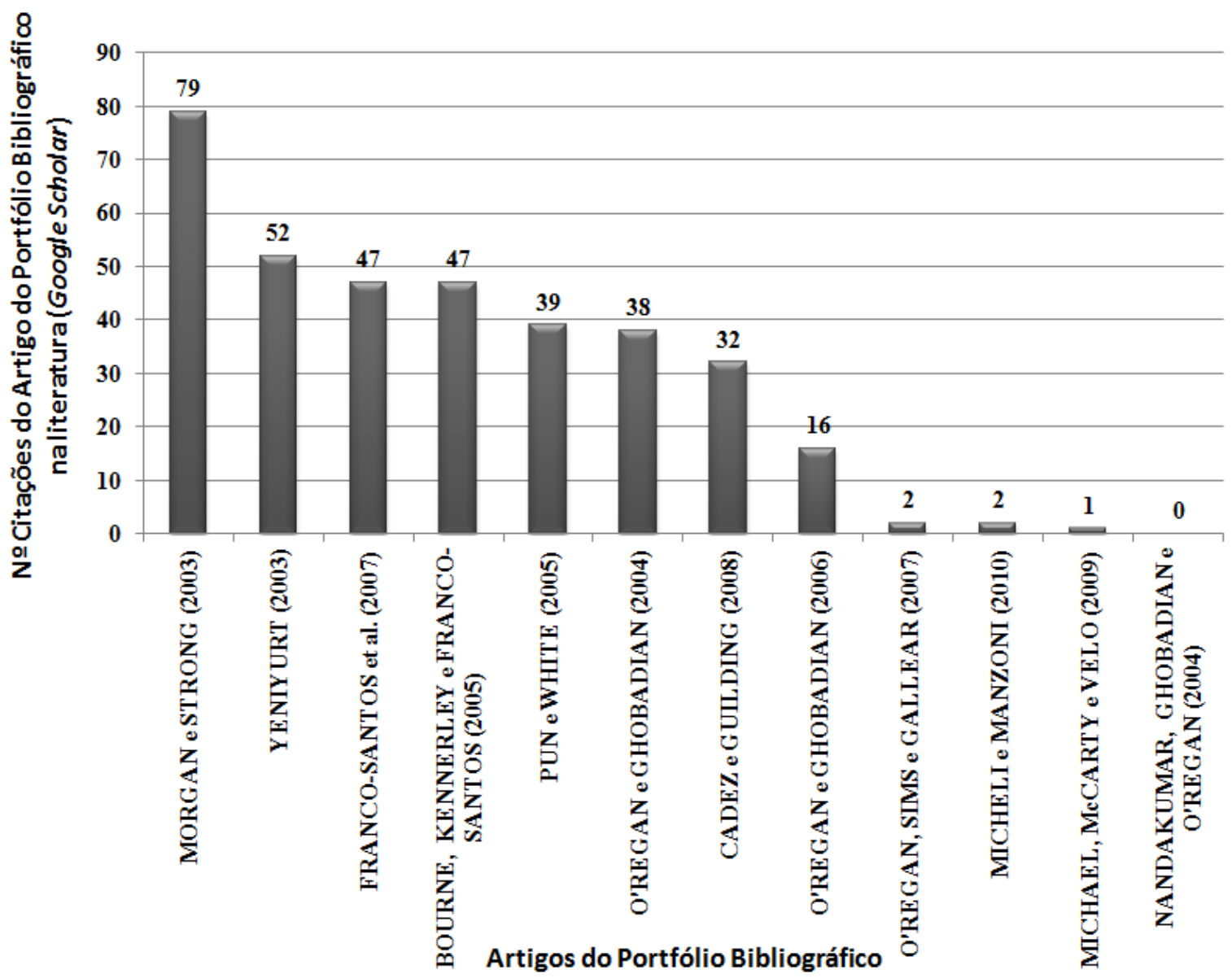

Fonte: Autoria própria (2012)

Pode-se observar que com o maior número de citações está o artigo de Morgan e Strong (2003), que tem o título “Business performance and dimensions of strategic orientation”, com 79 citações. O artigo de Yeniyurt (2003) - “A literature review and integrative performance measurement framework for multionational companies" - vêm em segundo com 52 citações.

A terceira análise dos artigos do portfólio consistiu em identificar os autores com maior participação no portfólio bibliográfico (Gráfico 4). 


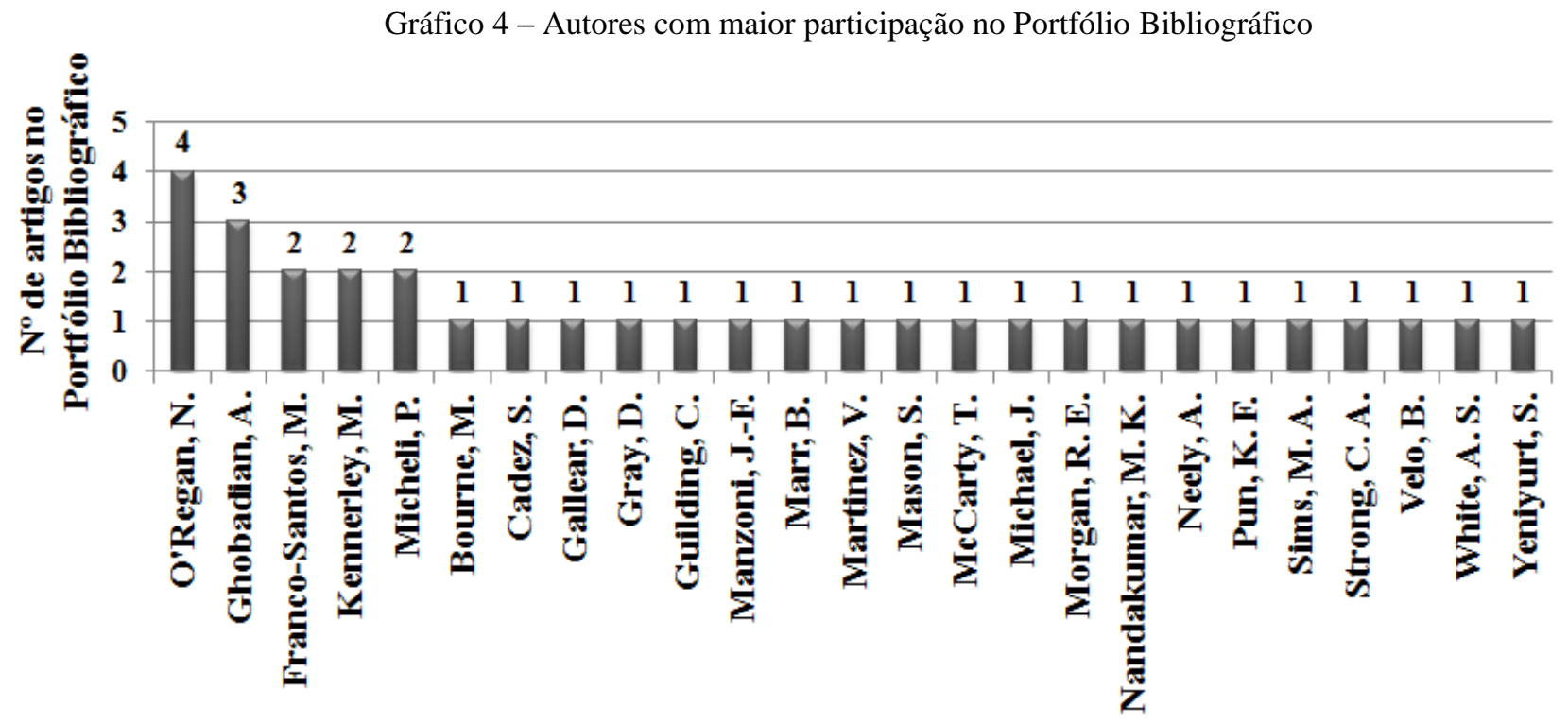

Autores do Portfólio Bibliográfico

Fonte: Autoria própria (2012)

Os autores que mais se destacam na amostra são Nicholas O'Regan e Abby Ghobadian com 04 e 03 artigos integrando o Portfólio bibliográfico, respectivamente.

Finalmente, a última análise encetada nesta dimensão da bibliometria, e apresentada no Gráfico 5, buscou estimar as palavras mais utilizadas no portfólio bibliográfico.

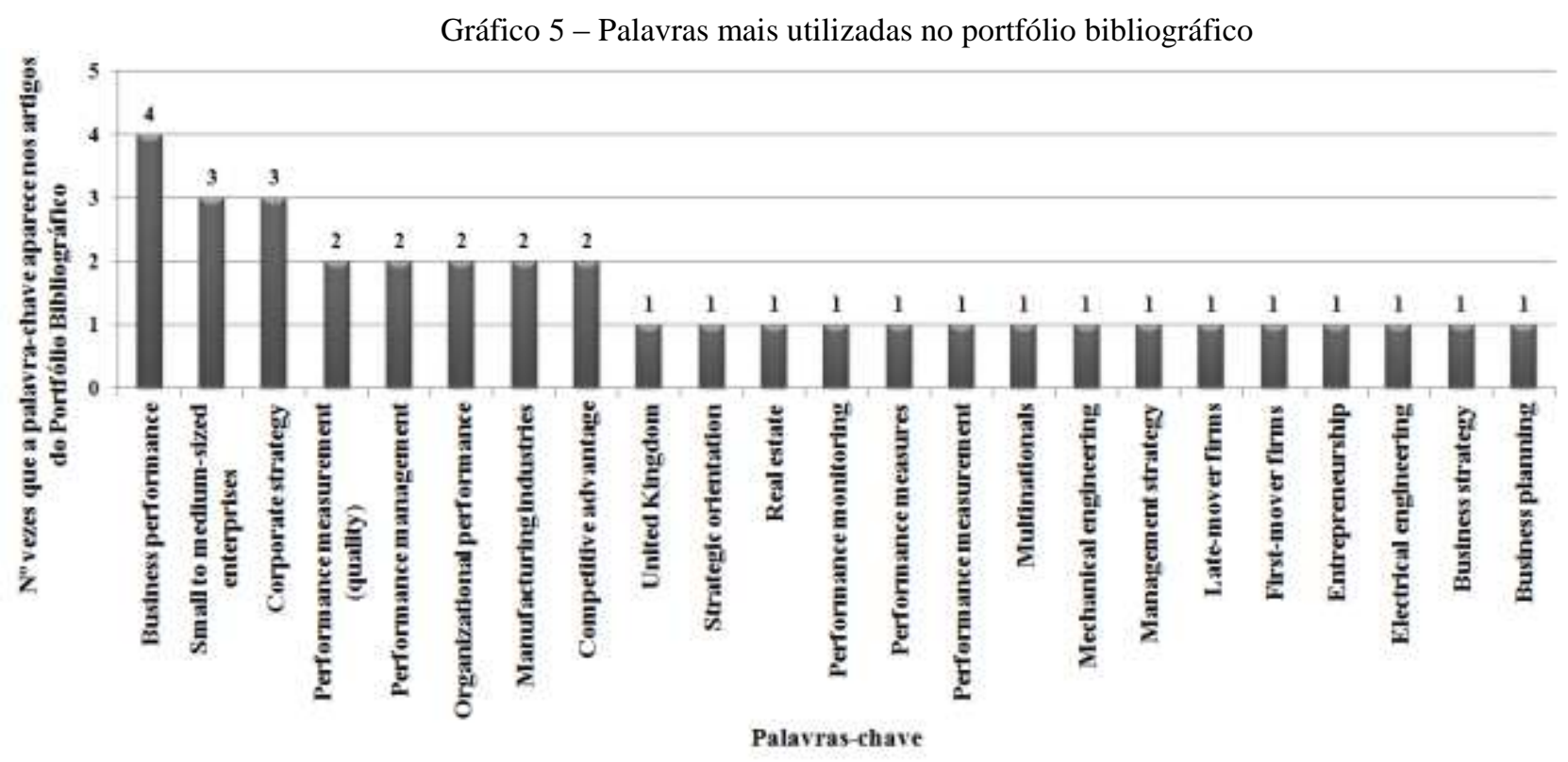

Fonte: Autoria própria (2012)

A palavra-chave que mais se destacou nos artigos do portfólio bibliográfico foi "Business performance" com quatro referências, seguida de "Small to medium-sized enterprises" $e$ "Corporate strategy", com três citações cada uma. 
Destaca-se que a palavra-chave "Corporate strategy" foi empregada neste trabalho para a seleção do portfólio bibliográfico.

\subsection{Análise bibliométrica das referências dos artigos selecionados}

Para esta análise utilizam-se as referências dos artigos selecionados, com o objetivo de identificar os autores, artigos e periódicos mais relevantes no contexto da pesquisa em questão.

As 447 referências bibliográficas constantes dos 12 artigos que compõem o portfólio bibliográfico foram analisadas, em primeiro plano, buscando observar a relevância dos periódicos (Gráfico 6).

Gráfico 6 - Relevância dos periódicos nas referências dos artigos do portfólio bibliográfico

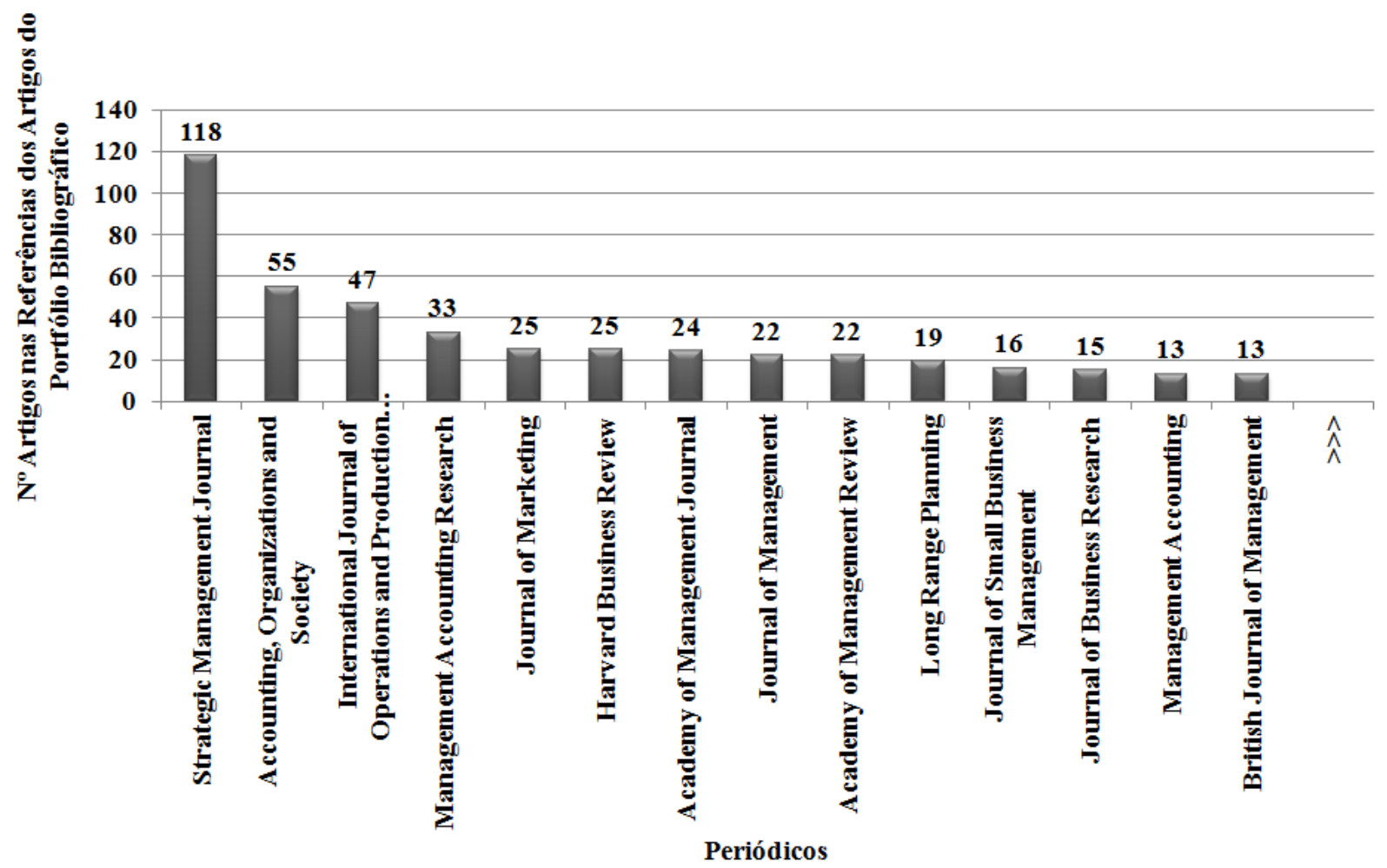

Fonte: Autoria própria (2012)

O periódico que mais se destaca é o Strategic Management Journal com 118 artigos nas referências dos artigos do portfólio bibliográfico. Em seguida se observa o periódico Accounting, Organization and Society com 55 artigos. O International Journal of Operations and Production Management apresentou 47 artigos, e o Management Accounting Research, 33 artigos.

A segunda análise teve a finalidade de identificar a relevância acadêmica dos artigos constantes das referências dos artigos do portfólio bibliográfico, por meio do número citações do artigos no Google Scholar (GOOGLE, 2011), conforme segue apresentado no Gráfico 7. 
Gráfico 7 - Reconhecimento acadêmico dos artigos das referências dos artigos do Portfólio Bibliográfico

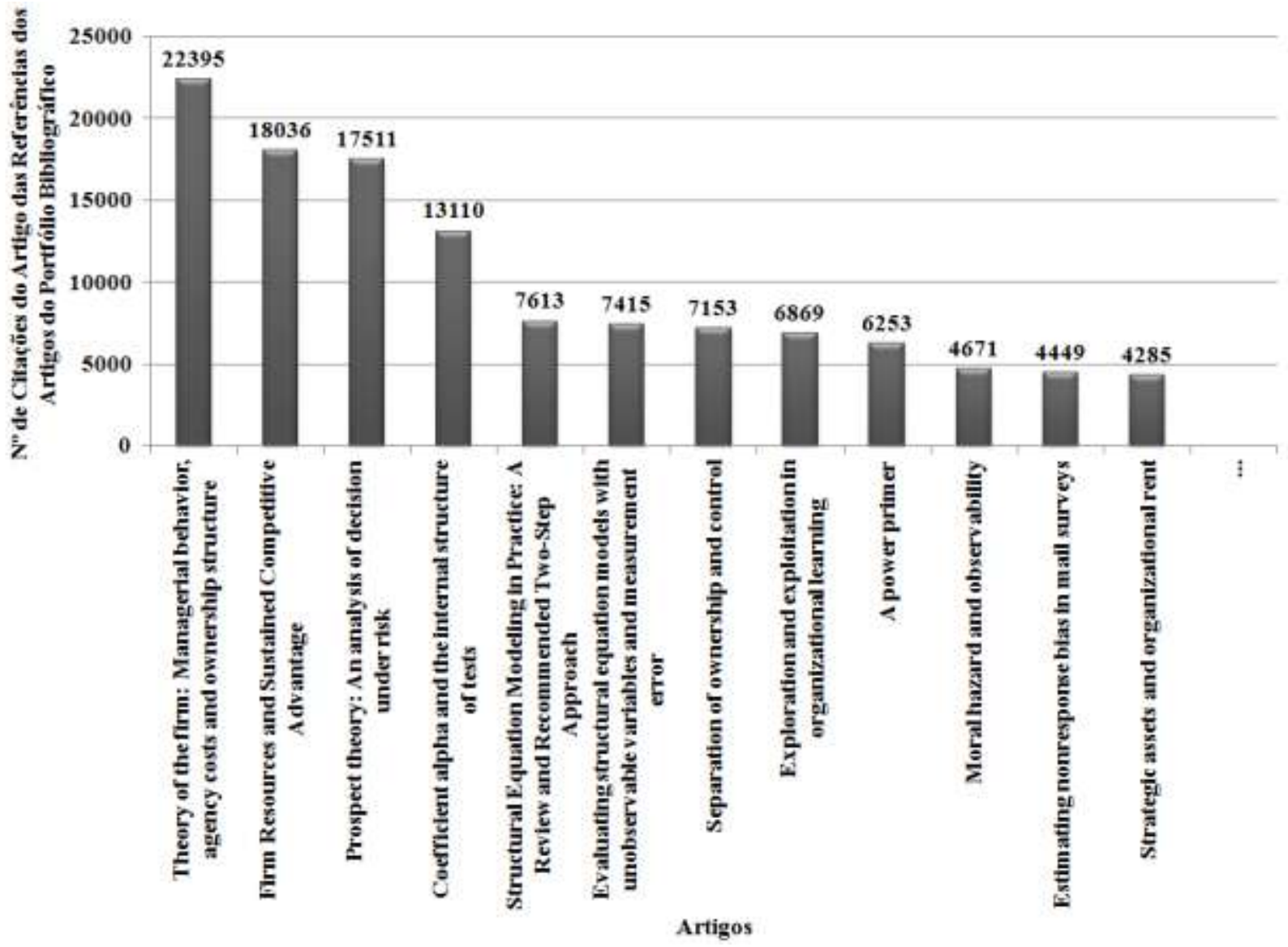

Fonte: Autoria própria (2012)

Pode-se observar no Gráfico 7 que o artigo com maior número de citações foi o trabalho intitulado "Theory of the firm: Managerial behavior", de Michael C. Jensen, com 22.395 citações.

Agora serão apresentados, no Gráfico 8, os resultados da análise empreendida para evidenciar os autores com maior participação nos artigos das referências bibliográficas do portfólio selecionado. 


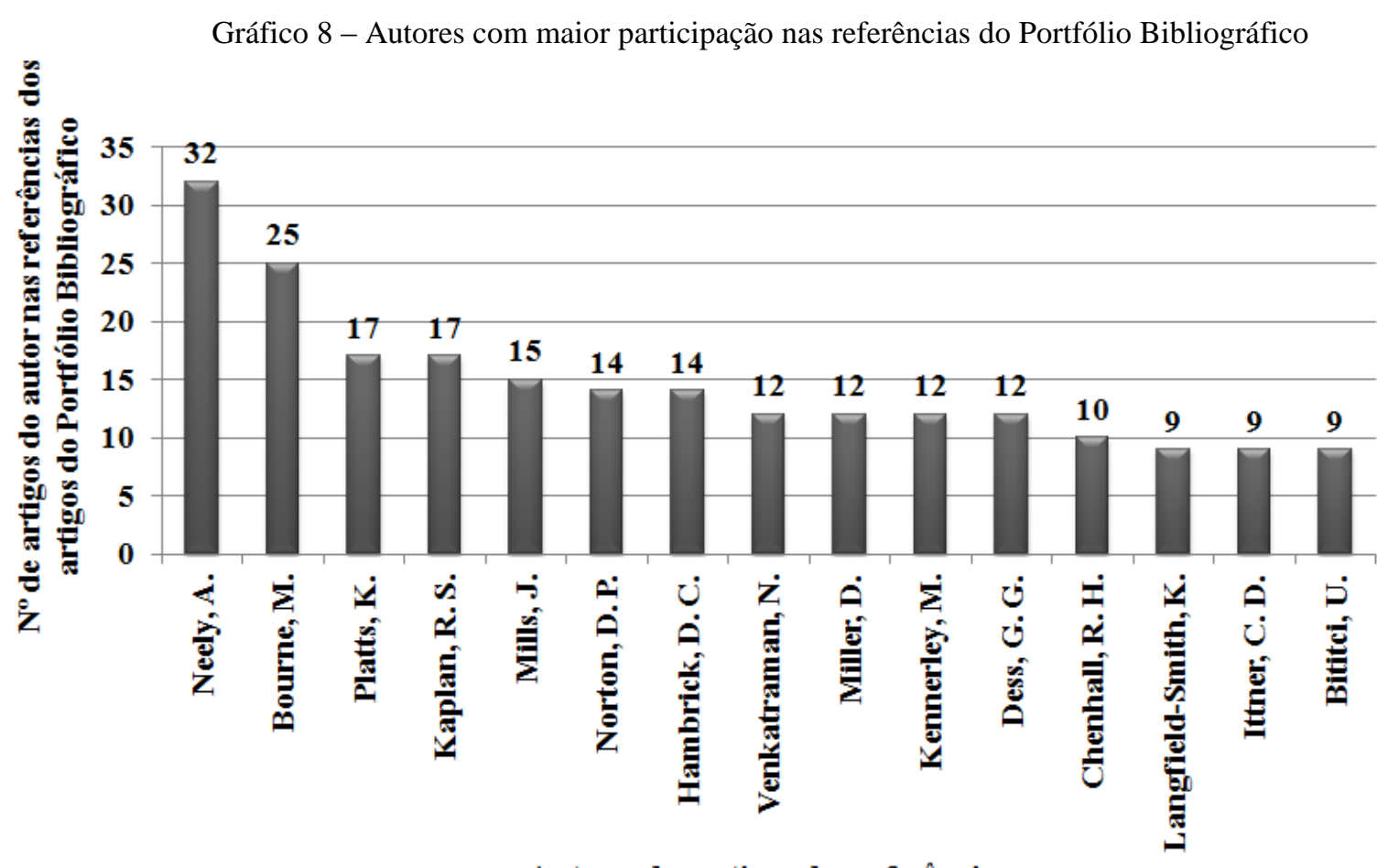

\section{Autores dos artigos das referências}

Fonte: Autoria própria (2012)

O autor que mais se destaca é A. Neely com 32 citações nas referências dos artigos do portfólio bibliográfico, seguido de M. Bourne com 25 citações. Com 17 citações seguem os autores K. Platts e R. S. Kaplan.

A próxima análise da bibliometria apura a participação dos autores nos artigos do portfólio bibliográfico e também nas referências destes artigos (Gráfico 9).

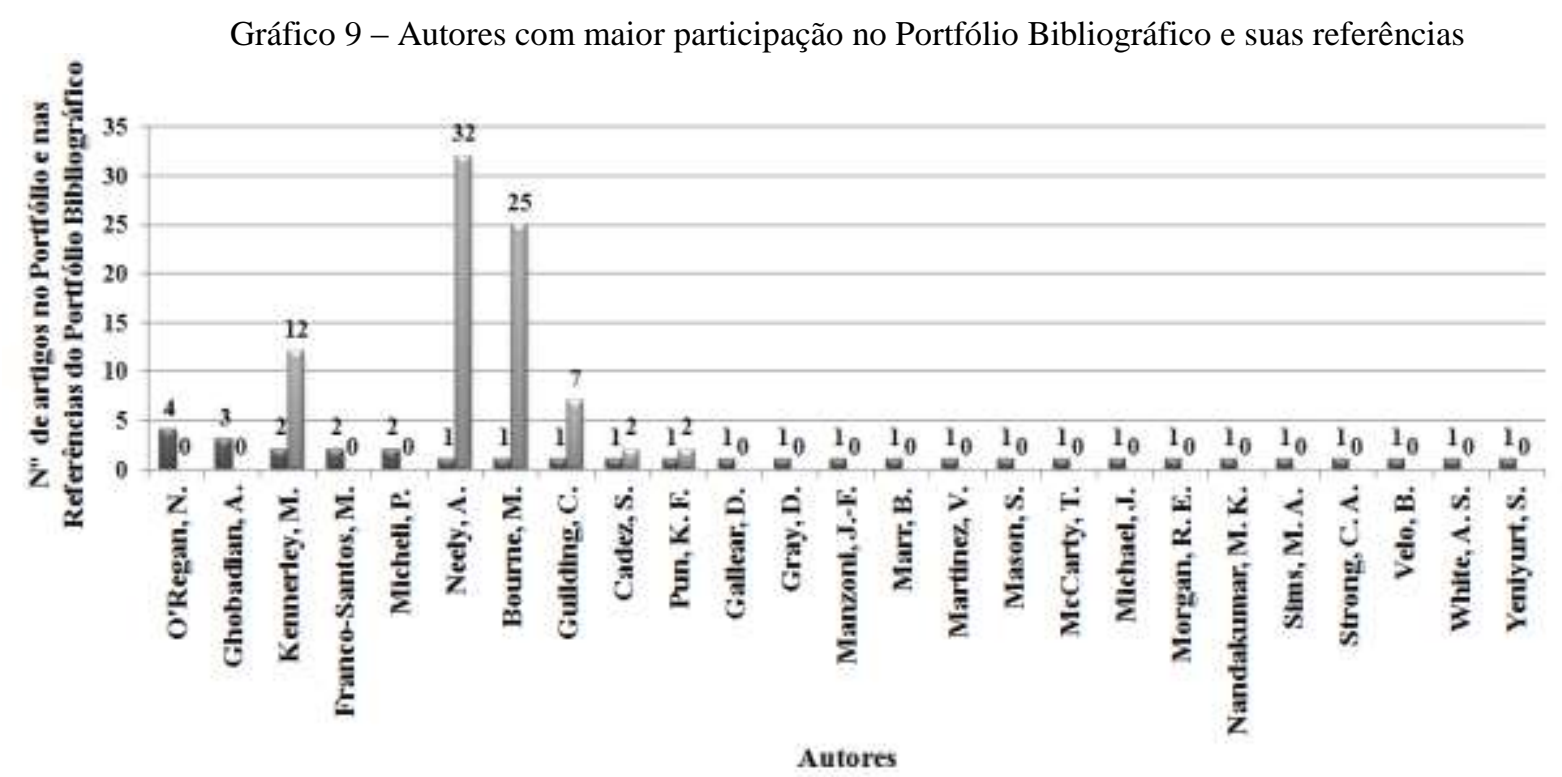

Fonte: Autoria própria (2012) 
Pode-se observar que os autores que mais se destacam, tanto no portfólio quanto nas referências, são: Nicholas O'regan, Abby Ghobadian, Pietro Micheli, Mike Kennerley, Monica Franco-Santos, K. F. Pun, Andrew Neely, Steve Marson, Veronica Martinez, Bernarde Marr, C. Guilding, Dina Gray, S. Cadez e Mike Bourne.

\subsection{Classificação dos artigos por sua relevância acadêmica na amostra}

Para a classificação dos artigos em face de sua relevância acadêmica na amostra, o método proposto por Ensslin et al (2010b) estabelece dois eixos de avaliação: (i) O número de citações que o artigo obteve desde a sua publicação (obtido por meio do Google Scholar); e, (ii) O número de citações do autor mais citado do artigo nas referências bibliográficas dos artigos do portfólio.

Neste sentido, empregando o princípio de Pareto, ficou definido que seriam destaques no que se refere ao eixo de avaliação dos artigos do portfólio (eixo das ordenadas) os artigos com 63 citações ou mais no Google Scholar, enquanto seriam autores destaque (no eixo das abscissas) aqueles com 25 citações ou mais nas referências do portfólio bibliográfico. Para demarcar estas delimitações foram apensadas duas linhas tracejadas no Gráfico 10.

Com a definição destes parâmetros, ficaram estabelecidos quadrantes com os seguintes significados: (i) Quadrante superior direito - artigos de destaque realizados por autores de destaque; (ii) Quadrante superior esquerdo - artigos de destaque; (iii) Quadrante inferior direito - artigos realizados por autores de destaque; e, (iv) Quadrante inferior esquerdo - artigos relevantes para o tema de pesquisa.

Como se depreende do Gráfico 10, pelos critérios estabelecidos não houve artigos de destaque realizados por autores de destaque. Como artigo de destaque transparece o trabalho de Morgan e Strong (2003), e como artigos realizados por autor de destaque, os artigos de Franco-Santos et al (2007), tendo Andrew Neely como autor de destaque, e Bourne, Kennerley e Franco-Santos (2005), com Mike Bourne se sobressaindo.

\section{Conclusão}

O objetivo deste trabalho centrou-se em apresentar um processo para selecionar referências bibliográficas para compor um referencial teórico sobre o contexto de avaliação de desempenho e gestão estratégica organizacional. 
Gráfico 10 - Artigos e seus autores de maior destaque na amostra

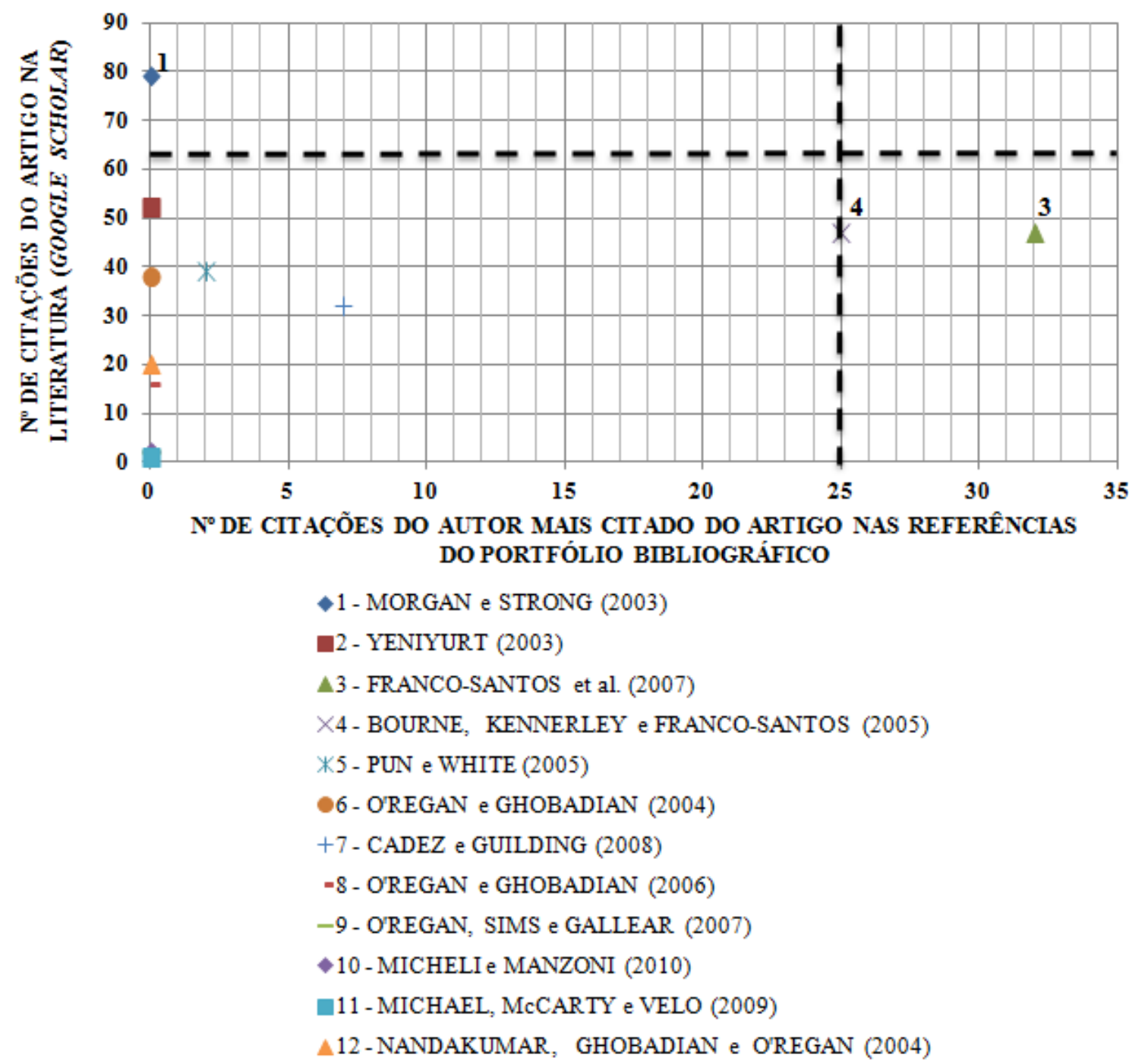

Fonte: Autoria própria (2012)

O artigo foi dividido em duas etapas consubstanciadas na construção do portfólio e na consecução da análise bibliométrica.

A construção do portfólio teve como objetivo selecionar artigos mais relevantes sobre o tema em questão. Por sua vez, a análise bibliométrica buscou averiguar na amostra selecionada os principais artigos, autores, periódicos e palavras-chave publicados nos últimos 10 anos sobre o tema avaliação de desempenho e a gestão estratégica organizacional.

O processo de construção do portfólio bibliográfico possibilitou realizar uma análise de 12.915 artigos, culminando com um portfólio final de 12 artigos alinhados com o tema e reconhecidos cientificamente.

$\mathrm{Na}$ análise bibliométrica foi evidenciado que o periódico com mais artigos publicados na amostra é o Journal of Manufacturing Technologyc Management. 
Em relação aos autores, o processo evidenciou as contribuições dos pesquisadores Nicholas O'Regan, com quatro trabalhos selecionados, Abby Ghobadian, com três trabalhos, Mike Kennerley, Monica Franco-Santos e Pietro Micheli com dois trabalhos cada um.

Quanto às palavras-chave as que mais se destacaram foram business performance, performance measurement e coporate strategy.

Além da análise bibliométrica dos artigos do portfólio, foi realizada a análise de suas referências bibliográficas, situação que permitiu evidenciar como periódicos de destaque o Strategic Management Journal e o Accounting e Organization and Society.

Quanto à análise dos autores, foram identificados como mais citados na amostra os pesquisadores Andrew Neely e Mike Bourne.

$\mathrm{Na}$ classificação de relevância acadêmica realizada sob a ótica de numero de citações do artigo e pelo número de citações do autor mais citado do artigo nas referências bibliográficas dos artigos selecionados no portfólio, destacaram-se os trabalhos de Morgan e Strong (2003), FrancoSantos et al (2007) e Bourne, Kennerley e Franco-Santos (2005).

Desta forma, pode-se asseverar que a pergunta de pesquisa - Como construir o conhecimento demandado por um pesquisador quando do início de uma pesquisa no tema gestão estratégica organizacional com foco nos resultados, segundo a percepção de seu gestor, a fim de propiciar-lhe as condições necessárias para, em um segundo momento, buscar as oportunidades para contribuir na temática escolhida? - foi respondida ao longo das seções 3 e 4.

Da mesma forma, o objetivo geral de construir, no pesquisador, o conhecimento necessário para orientá-lo onde buscar as oportunidades (lacunas) para pesquisar sobre o tema gestão estratégica sob o enfoque da avaliação de desempenho, e os objetivos específicos - (i) Selecionar um Portfólio Bibliográfico relevante sobre a gestão estratégica sob o viés da avaliação de desempenho, e (ii) Realizar análise bibliométrica do portfólio bibliográfico selecionado e de suas referências, visando identificar os periódicos, artigos, autores e palavras-chave de destaque também foram contemplados nas seções 3 e 4 .

As limitações desta pesquisa foram as seguintes: (i) delimitação do campo amostral, pois neste trabalho foram utilizados apenas quatro bancos de dados; (ii) utilização apenas de trabalhos internacionais; e, (iii) utilização apenas de periódicos, não considerando teses, dissertações, monografias, congressos e livros.

Finalmente, a título de recomendações para futuras pesquisas sugere-se: (i) a utilização de mais banco de dados do portal da Capes; (ii) considerar banco de dados nacionais; e, (iii) utilização de outros trabalhos, como teses, dissertações, livros e congressos científicos. 


\begin{abstract}
This article aims to make the selection of a theoretical issue related to organizational strategic management, with a focus on performance evaluation through a structured process called ProKnowC (Knowledge Development Process - Constructivist), as well as develop the analysis bibliometric this portfolio literature, highlighting articles, authors and journals and more aligned with the subject more relevant in the academic sample. The process allowed bibliographic build a portfolio composed of 12 articles, selected from four international databases. Bibliometric analysis in the articles were analyzed and their selected portfolio of references, allowing to determine, for the sample, the most relevant articles, authors, keywords and periodicals that published most on the subject in question.
\end{abstract}

Key-words: performance evaluation, strategic management organizational, ProKnow-C, analysis bibliometrics.

\title{
Referências
}

BOURNE, M.; KENNERLEY, M.; FRANCO-SANTOS, M. Managing through measures: a study of impact on performance. Journal of Manufacturing Technology Management, v. 16, n.4, p. 373-395, 2005.

cross ref

CADEZ, S.; GUILDING, C. An exploratory investigation of an integrated contingency model of strategic management accounting. Accounting Organizations and Society, v. 33, p. 836-863, 2008.

cross ${ }^{\text {ref }}$

CAPES, Coordenação de Aperfeiçoamento de Pessoal de Nível Superior. Disponível em: < http://www.capes.gov.br/>. Acesso em 13 de mar. 2011.

CRAVENS, K. S.; OLIVER, E. G.; STEWART, J. S. Can a positive approach to performance evaluation help accomphish your goals? Business Horizons, v. 53, n. 3, p. 269-279, 2010.

cross'r

ENSSlin, L., GIFFHORN, E., ENSSLIN, S. R., PETRI, S. M. ; VIANNA, W. B. Avaliação do Desempenho de Empresas Terceirizadas com o Uso da Metodologia Multicritério de Apoio à Decisão- Construtivista. Revista Pesquisa Operacional, v.30, n.1, p.125-152, 2010a.

ENSSLIN, L., ENSSLIN, S. R., LACERDA, R. T. O. \& TASCA, J. E. ProKnow-C, Knowledge Development Process - Constructivist. Processo técnico com patente de registro pendente junto ao INPI. Brasil, $2010 \mathrm{~b}$.

FRANCO, M. A. S. Pedagogia da Pesquisa-Ação. Revista Educação e Pesquisa. São Paulo, v. 31, n. 3, set/dez, p. 483$502,2005$.

FRANCO-SANTOS, M.; KENNERLEY, M.; MICHELI, P. ; MARTINEZ, V.; MASON, S.; MARR, B.;GRAY, D.; NEELY, A.. Towards a definition of a business performance measurement system. International Journal of Operations \& Production Management, v. 27, n.8, p.784-801, 2007.

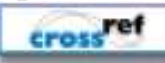

GIL, A. C. Métodos e Técnicas de Pesquisa Social. São Paulo: Atlas, 1999.

GOOGLE. Google Scholar. Disponível em: < http://scholar.google.com.br/ >. Acesso em 13 mar. 2011.

KIM, W.C.; MAUBOURGNE, R. A estratégia do oceano azul: como criar novos mercados e tornar a concorrência irrelevante. Rio de Janeiro: Elsevier, 16 ed., 2005.

LACERDA, R. T. O.; ENSSLIN, L.; ENSSLIN, S. R. A Performance Measurement Framework in Portfolio Management: A Constructivist Case. Management Decision, v. 49, p. 1-15, 2011.

cross ref 
LAKATOS, E. M.; MARCONI, M. A. Fundamentos de Metodologia Científica. São Paulo: Atlas, 6 ed., 2006.

LOHMAN, C.; FORTUIN, L.; WOUTERS, M. Designing a performance measurement system: a case study. European Journal of Operational Research, v. 156, n. 2, p. 267-286, 2004.

cross ref

MALDONADO, M. U.; SILVA SANTOS, J. L.; SANTOS, R. N. M. Inovação e Conhecimento Organizacional: Um mapeamento bibliométrico das publicações cientificas até 2009. In: XXXIV ENCONTRO DA ANPAD, Rio de Janeiro, set., 2010.

MICHAEL, J.; THOMAS, M.; VELO, B. Performance measurement in corporate real estate. Journal of Corporate Real Estate, v. 11, n. 2, p.106-114, 2009.

cross ref

MICHELI, P.; J.-F. MANZONI Strategic Performance Measurement: Benefits, Limitations and Paradoxes. Long Range Planning, v. 43, n. 4, p.465-476, 2010.

eross ref

MINAYO, M. C. S.; DESLANDES, S. F.; GOMES, R. Pesquisa Social: Teoria, método e criatividade. Rio de janeiro: Vozes, 25 ed., 2007.

MINTZBERG, H.; ASHLSTRAND, B.; LAMPEL, J. Safári de estratégias. Porto Alegre: Bookland, 3 ed., 2000.

MORGAN, R. E.; C. A. STRONG Business performance and dimensions of strategic orientation. Journal of Business Research , v. 56, n. 3, p.163-176, 2003.

cross ref

NANDAKUMAR, M. K., G. ABBY, et al. Generic strategies and performance â€ evidence from manufacturing firms. International Journal of Productivity and Performance Management, v. 60, n.3, p.222-251, 2004.

cross ref

O'REGAN, N.; SIMS, M. A.; GALLEAR, D.. Leaders, loungers, laggards: The strategic-planning-environmentperformance relationship re-visited in manufacturing SMEs. Journal of Manufacturing Technology Management, v. 19, n.1, p.6-21, 2007.

cross ref

O'REGAN, N.; GHOBADIAN, A. The importance of capabilities for strategic direction and performance. Management Decision, v. 42, n.2, 292-313, 2004.

cross ref

O'REGAN, N.; GHOBADIAN, A. Perceptions of generic strategies of small and medium sized engineering and electronics manufacturers in the UK: The applicability of the Miles and Snow typology. Journal of Manufacturing Technology Management, v. 17, n.5, p. 603-620, 2006.

cross ref

PELAEZ, V.; SZMRECSÁNYI, T. Economia da inovação tecnológica. São Paulo: Hucitec, 2006.

PEREGO, P.; F. HARTMANN Aligning Performance Measurement Systems With Strategy: The Case of Environmental Strategy. Abacus-a Journal of Accounting Finance and Business Studies, v. 45, n.4, p. 397-428, 2009.

PUN, K. F.; A. S. WHITE A performance measurement paradigm for integrating strategy formulation: A review of systems and frameworks. International Journal of Management Reviews, v. 7, n.1, p.49-71, 2005.

cross ref 
SENGUN, Y. A literature review and integrative performance measurement framework for multinational companies. Marketing Intelligence \& Planning, v.21, n.3, p.134-142, 2003.

cross ref

SILVA, E. H. D. R.; LIMA, E. P.; COSTA, S. E. G. Análise da produção acadêmica brasileira em medição de desempenho e modelos de gestão. Revista Gestão Industrial, v. 5, n. 3, p. 198-218, 2009.

cross ref

TASCA, J. E.; ENSSLIN, L.; ENSSLIN, S. R.; ALVES; M. B. M. An approach for selecting a theoretical framework for the evaluation of training programs. Journal of European Industrial Training, v. 34, n. 7, p. 631-655, 2010.

cross ref

QUINTELLA, O. M.; LIMA, G. B. A. O balanced scorecard como ferramenta para implantação da estratégia: uma proposta de implantação. Revista Gestão Industrial, v. 1, n. 4, p.34-41, 2005.

cross ref

\section{Dados dos Autores:}

Nome completo: Caroline Rodrigues Vaz

Filiação institucional: UFSC - Universidade Federal de Santa Catarina

Departamento: PPGEP

Função ou cargo ocupado: Doutoranda em Engenharia de Produção

Endereço completo para correspondência (bairro, cidade, estado, país e CEP): Campus Universitário - Trindade, Caixa Postal 476 - CEP 88040-900

Telefones para contato: 48 3722-7107

e-mail: caroline-vaz@hotmail.com

Nome completo: Jorge Eduardo Tasca

Filiação institucional: UFSC - Universidade Federal de Santa Catarina

Departamento: PPGEP

Função ou cargo ocupado: Doutorando em Engenharia de Produção

Endereço completo para correspondência (bairro, cidade, estado, país e CEP): Campus Universitário - Trindade, Caixa Postal 476 - CEP 88040-900

Telefones para contato:

e-mail: jorgetasca@gmail.com

\section{Nome completo: Leonardo Ensslin}

Filiação institucional: UFSC - Universidade Federal de Santa Catarina,

Departamento: PPGEP

Função ou cargo ocupado: Professor PhD do curso de Pós-Graduação em Engenharia de Produção 
Endereço completo para correspondência (bairro, cidade, estado, país e CEP): Campus Universitário - Trindade, Caixa Postal 476 - CEP 88040-900

Telefones para contato:

e-mail: leonardoensslin@gmail.com

Nome completo: Sandra Rolim Ensslin

Filiação institucional: UFSC - Universidade Federal de Santa Catarina

Departamento: PPGEP

Função ou cargo ocupado: Professora Doutora do curso de Pós-Graduação em Engenharia de Produção

Endereço completo para correspondência (bairro, cidade, estado, país e CEP): Campus Universitário - Trindade, Caixa Postal 476 - CEP 88040-900

Telefones para contato:

e-mail:sensslin@gmail.com

Nome completo: Paulo Mauricio Selig

Filiação institucional: UFSC - Universidade Federal de Santa Catarina

Departamento: PPGEP

Função ou cargo ocupado: Professor Doutor do curso de Pós-Graduação em Engenharia de Produção e Coordenador do Curso de Pós-Graduação em Engenharia e Gestão do Conhecimento

Endereço completo para correspondência (bairro, cidade, estado, país e CEP): Campus Universitário - Trindade, Caixa Postal 476 - CEP 88040-900

Telefones para contato: 48 3722-7107

e-mail:selig@deps.ufsc.br

Enviado em: 08/07/2011

Aprovado em: 09/08/2012 